\title{
Responsabilidad de proteger y revolución, el rol de las Naciones Unidas en la guerra civil libia ${ }^{1}$
}

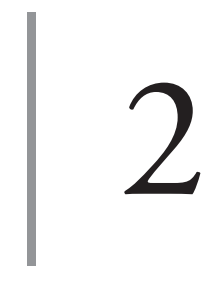

https://doi.org/10.21830/9789585318328.02

\author{
Juan Camilo Mejía Prieto \\ Escuela Militar de Cadetes "General José María Córdova”
}

\section{Resumen}

El presente capítulo aborda las dinámicas que desencadenaron la primera guerra civil libia, a través de un recorrido histórico que termina con el inicio de la era republicana, profundamente marcada por la ideología gadafista. Se exponen los antecedentes inmediatos que originaron las hostilidades, así como las partes enfrentadas y su respectiva valoración de potenciales. Se aborda, igualmente, la significativa participación de la OTAN (en cabeza, principalmente, de Estados Unidos., Reino Unido y Francia) en cumplimiento de las resoluciones emitidas por el Consejo de Seguridad de las Naciones Unidas, evidenciando la clara alianza militar entre actores estatales y no estatales, que finalmente derrocaron al régimen tras la muerte del dictador. Finalmente, se cierra con un recorrido cronológico a través del desarrollo de la campaña militar, para concluir, a través de una breve discusión, con las implicaciones de esta intervención en la seguridad internacional y, en particular, en la denominada 'responsabilidad de proteger'.

Palabras clave: Gadafi, intervención, Libia, OTAN, revolución, R2P.

1 Este capítulo hace parte de los resultados del proyecto de investigación "Mecanismos del sistema de Naciones Unidas para la resolución de conflictos armados contemporáneos", del Grupo de Investigación en Ciencias Militares de la Escuela Militar de Cadetes "General José María Córdova, registrado con el código COL0082556 de Minciencias. Los puntos de vista y los resultados de este artículo pertenecen al autor y no reflejan necesariamente los de las instituciones participantes.

2 Profesional en ciencias militares y administrador de empresas. Especialista en conducción y administración de unidades militares. Especialista en administración de recursos militares para la defensa nacional. Magíster en Inteligencia Estratégica (Escuela de Inteligencia y Contrainteligencia). Magíster en Estudios de Defensa (Royal Military College of Canada). ORCID: https://orcid.org/0000-0002-3187-1015 - Contacto: juan.mejia@buzonejercito.mil.co 


\section{Introducción}

A lo largo de la historia, el norte de África ha sido un importante territorio para imperios y Estados, cuya influencia ha buscado extenderse a lo largo del mar Mediterráneo, para el caso en cuestión, libio. Las profundas divisiones sociales, su compleja historia colonial, y la presencia de recursos tan importantes como el petróleo, se suman a las condiciones geopolíticas que han favorecido directa o indirectamente el desarrollo de varios conflictos armados. De igual forma, la privilegiada ubicación de Libia con respecto a Europa Occidental la hizo un blanco importante de la tensión bipolar de la Guerra Fría. La revolución libia de 2011 no es simplemente una expresión de la Primavera Árabe, sino la consecuencia de un intrincado entramado de procesos sociales, políticos y económicos que tienen su origen en la primera mitad del siglo XX.

Aunque es indudable que la represión violenta de la Primavera Árabe obligó a una respuesta de la comunidad internacional, la responsabilidad de proteger fue extendida para favorecer el derrocamiento de Muamar Gadafi tras una intervención militar liderada por la Organización del Tratado del Atlántico Norte (en adelante OTAN). En 2011, la guerra civil enfrentó a una complicada mezcla de actores estatales y no estatales, cuyos triunfadores no lograron estabilizar al país, generando así las condiciones para una segunda guerra civil que iniciaría en 2014.

En este capítulo se aborda la revolución libia de 2011, con el fin de responder las siguientes preguntas: ¡cuáles fueron las causas y antecedentes de la revolución libia de 2011?, ¿quiénes fueron los actores enfrentados y qué apoyo recibieron?, ¿cuál fue el papel desempeñado por la Organización de las Naciones Unidas (en adelante ONU) antes y durante el conflicto?, ¿cómo se desarrolló este hasta lograr el derrocamiento del régimen gadafista?

Con el propósito de dar respuesta a esos interrogantes, el texto está construido alrededor de tres aproximaciones. Inicialmente, se exponen las circunstancias históricas de Libia desde su periodo colonial hasta su independencia, explicando las consideraciones ideológicas gadafistas presentes en el Libro Verde. Posteriormente, se analizan los antecedentes inmediatos a las hostili- 
dades y los bandos enfrentados, teniendo en cuenta su organización política, militar y su apoyo internacional. Por último, se aborda el rol desempeñado por la ONU, además del desarrollo cronológico y geográfico del conflicto, para cerrar con el derrocamiento de Muamar Gadafi.

\section{Breve reseña histórica}

La referencia más antigua que se tiene acerca de asentamientos humanos en la actual Libia proviene de las paletas egipcias que mencionan la interacción con el pueblo Tehenu durante el periodo predinástico. Los Tehenu fueron asociados con commodities, como madera, resina, ungüentos y animales de pastoreo, que fueron necesarios para la unificación egipcia y el éxito posterior de la dinastía faraónica (Moreno, 2014).

Su presencia a lo largo de la costa mediterránea hasta el delta del río Nilo sugiere que el pueblo Tehenu fue el poder extranjero más importante desde el periodo predinástico (3200 a. C.) hasta el final del Imperio Antiguo de Egipto (2134 a. C.). Su derrota, por parte del rey Narmer, se considera tan fundamental en la historia egipcia que su representación aparece dentro de la iconografía de los faraones Sahura, Nyuserra y Neferkara Pepy (Hofmann, 2005).

El territorio fue colonizado posteriormente, en el siglo VII a. C, por griegos provenientes de la isla de Tera (actual Santorini), que huían de una severa sequía y sobrepoblación. Tras su llegada, la región fue llamada Cirenaica y los nómadas allí presentes fueron denominados "libios", en concordancia con la expresión "lebu", referida a ellos por los antiguos egipcios (La Boda, 1994). Desde el siglo IV a. C. el estado Cartaginés (actual Túnez) estableció centros de comercio con Trípoli, capital de Tripolitania (occidente de Cirenaica, actual Libia).

Tras el desarrollo de las Guerras Púnicas (264 a. C.-146 d. C.), Cartago es saqueada y la región pasa a integrar la provincia romana de Africa Proconsularis. En el siglo V d. C., el rey Genserico de los Vándalos arrebata el control del Mediterráneo a Roma y convierte a Cartago en su capital. Tras la muerte de Mahoma (632 d. C.), el Califato Rashidun (632-661 d. C.), ya en guerra con el Imperio bizantino, conquistó Cirenaica y Tripolitania al extender su dominio 
desde la actual Siria hasta la actual Túnez. Bajo el dominio musulmán, la región conformaría la provincia de Barqah, nombrada así en referencia a Barca (actual Libia), ciudad que posteriormente sería su capital durante el califato Fatimí (909-1171).

Tripolitania y Cirenaica estuvieron bajo el control de árabes y bereberes durante casi un milenio, hasta la expansión del Imperio otomano a lo largo del mar Mediterráneo (Siebens \& Case, 2012). Solimán el Magnífico, favorecido en gran parte con el colapso del Imperio bizantino, en 1453, asedia con éxito a Trípoli en 1551, convirtiendo las provincias de Cirenaica, Tripolitania y Fezán en parte del Imperio otomano.

Entre los siglos XVI y XIX, Marruecos y los entonces Estados vasallos otomanos de Argelia, Túnez y Tripolitania patrocinaron la piratería a lo largo del Mediterráneo, ocasionando las guerras Berberiscas, que finalizan con la victoria de Estados Unidos, Suecia y el Reino de Sicilia, en 1816. Mientras que Argelia y Túnez son colonizados por Francia, en 1830 y 1881, Tripolitania regresa al control otomano, en 1835.

La guerra ítalo-turca (1911-1912) culmina con la captura italiana del Valiato Otomano de Tripolitania, es decir, con la ocupación de las provincias de Cirenaica, Tripolitania y Fezán, que se convertirían en las colonias de Tripolitania y Cirenaica italianas. Ambas colonias se unifican en 1934 en la llamada Libia italiana. La resistencia a la ocupación italiana fue liderada por la orden sufista Sanusí, que en abierta oposición a Benito Mussolini padeció la denominada 'Pacificación de Libia', la cual ocasionó la muerte de 225.000 personas, un cuarto de la población de Cirenaica (Mann, 2005).

Desde el exilio en Egipto, el líder sanusí Muhammad Idris al-Senussi pactó una alianza con el Reino Unido, que materializó con el apoyo irrestricto a los Aliados durante la Segunda Guerra Mundial. Tras la guerra, Libia quedó bajo el control de fuerzas británicas en Cirenaica y Tripolitania, mientras que las tropas francesas controlaban Fezán (Vandewalle, 2012). En 1946 se crea en Damasco el congreso Umar al-Mukhtar, con el fin de lograr la independencia de Libia y de otras naciones del Magreb que se consideraban parte del mundo árabe (Baldinetti, 2014).

El futuro de Libia fue puesto en consideración en la Asamblea General de las Naciones Unidas en 1948, favoreciendo su independencia por encima de 
las pretensiones británicas y francesas de mantener el control colonial logrado tras la guerra (Vandewalle, 2012). En 1949, la Resolución 289 de las Naciones Unidas estableció, como plazo máximo, el mes de enero de 1952 para hacer efectiva la independencia libia.

Muhammad Idris al-Senussi, apoyado por Estados Unidos y el Reino Unido, es declarado Rey de Libia en 1951 y su alianza con las potencias occidentales favorece la instalación de bases militares, que se convertirían en un componente fundamental para la OTAN en el Mediterráneo durante la Guerra Fría (Brace, 1972). Mientras atendía un tratamiento médico en Turquía, en 1969, Idris I de Libia es depuesto por un golpe de Estado liderado por el coronel Muamar Gadafi, dando comienzo al periodo dictatorial que finalizará con el conflicto armado que aborda este capítulo.

\section{Periodo republicano libio}

El Movimiento de Oficiales Libres, promotor de la Revolución Egipcia de 1952, fue la cuna ideológica que instigaría, en 1969, la revolución socialista en Libia comandada por Gadafi, quien estudió la Filosofía de la Revolución de Gamal Abdel Nasser, líder político que desde 1954 se convertiría en el máximo representante del panarabismo y el socialismo árabe hasta su muerte, en 1970. En 1961, el líder libio afirmaría que "es para Nasser, que todos nosotros debemos buscar la personalidad y el magnetismo que él aplica sobre los jóvenes árabes, [aquel] que ofrece la única esperanza de recuperar la independencia y grandeza de nuestro propio país" (Olivier, 1980, p. 88).

La revolución del Primero de Septiembre (1969) puso fin al breve periodo monárquico de Idris I y permitió la creación de la República Árabe Libia. La joven república fue controlada de facto por Muamar Gadafi, quien se desempeñaba como secretario general del Congreso General del Pueblo (anteriormente Consejo de Comando Revolucionario). En 1979, tras renunciar a sus funciones públicas, Gadafi es nombrado de forma vitalicia "Hermano Líder y Guía de la Revolución” (U. S. Department of State, 2004).

Desde entonces, Gadafi se identificó a sí mismo como un "filósofo estadista" (Bazzi, 2011), una figura simbólica dentro de la estructura del gobierno 
libio que, supuestamente, carecía de autoridad para gobernar. Tal y como llegó a aseverar en 2011: "Personas como la Reina Isabel II del Reino Unido no tienen la autoridad para promulgar leyes oficiales, y esa exactamente es mi situación” (Bates, 2011).

En 1977, Libia se convierte oficialmente en un Estado socialista tras la Declaración de Sabha, mediante la cual, el Congreso General del Pueblo disuelve la República Árabe Libia que es sustituida por la Gran Yamahiriya Árabe Libia Popular Socialista. El neologismo yamahiriya, acuñado por Gadafi en el Libro Verde, se usó para definir a Libia como el Estado "de las masas", una mezcla los nacionalismos árabe y africano, socialismo, democracia directa y un sistema moral islámico (Al-Qadhafi, 1975). La adopción de la Tercera Teoría Universal se argumenta, entonces, para la nación libia, como una alternativa a la bipolaridad de los modelos político-económicos de la Guerra Fría (Al-Kadhdhāfī, 1974 como se cita en Hjärpe, 1976):

Encontramos el sistema occidental basado en la explotación por individuos de la comunidad donde la regla indica la "supervivencia del más fuerte", lo cual ha reducido la sociedad a un montón de familias rotas, desgarradas por el crimen, el vicio y la degeneración de los valores. Nuestra nación también estudió el sistema oriental basado en la explotación de individuos por un partido en nombre de la dictadura de una clase, donde los seres humanos no tienen libertad y están sujetos a ideas absolutamente materialistas las cuales contradicen los valores humanos. (p. 63)

El resto del periodo republicano libio estuvo marcado por una clara alineación al Bloque Soviético, a pesar de considerarse una nación no alineada desde 1964 (Non-Aligned Movement, 2020).

En la Declaración de Potsdam (1945), el ministro de relaciones exteriores soviético explicó el deseo de la Unión Soviética de proyectarse en el Mediterráneo y exigió que dicha presencia fuera precisamente en Libia (St. John, 1982). Tales intereses soviéticos no habían podido ser materializados durante la ocupación británico-francesa de Tripolitania, Cirenaica y Fezán, al terminar la Segunda Guerra Mundial, y mucho menos durante el reinado de Idris I, quien tenía una clara inclinación a favorecer los intereses de Estados Unidos y el Reino Unido en la región. 
Sin duda, la revolución del Primero de Septiembre facilitó la penetración soviética en el continente africano a través de Libia, que rápidamente se convertiría en el segundo importador de armas más grande del mundo (solo superado por Irán), 75\% de las cuales provenía de la Unión Soviética y cuyo valor aproximado ascendía a 25 billones $^{3}$ de dólares, (Lutterbeck, 2009).

Aunque desde 1979 Libia fue incluida por los Estados Unidos en la lista de países patrocinadores del terrorismo internacional, el final del periodo gadafista estuvo particularmente marcado por fuertes sanciones económicas derivadas del patrocinio de tales actividades. ${ }^{4}$ Entre ellas, la más renombrada fue el atentado al vuelo 103 de Pan American World Airways, que dejó como saldo la muerte de 270 personas en 1988.

A través de las sanciones económicas, Gadafi se vio obligado a extraditar a Abdelbaset al-Megrahi, en 1999, un supuesto Oficial de Inteligencia libio acusado desde 1991 por Estados Unidos y el Reino Unido de planear el ataque. Al-Megrahi fue condenado en 2000 por una corte escocesa en el Reino de los Países Bajos, siendo el único responsable capturado por tales hechos.

Libia aceptó en 2003 su responsabilidad en varios actos terroristas, tuvo que renunciar abiertamente al patrocinio del terrorismo y accedió al pago de una compensación a las familias de las víctimas (United Nations, 2003). El pago total ascendió a $£ 1$ millón de libras esterlinas, no solo por las víctimas del vuelo 103, sino también por aquellas del atentado en la discoteca berlinesa Le Belle (1986), en el que fueron heridas 229 personas y 3 perdieron la vida (Erlanger, 2011; Weaver, 2008).

\section{Ideología gadafista}

Gadafi plasmó su ideología política en el Libro Verde (1975), una clara emulación de lo que el Libro Rojo representó para el régimen de Mao Tse Tung a partir de 1964. El texto, referencia fundamental de la dictadura, se enseñó a cada niño en las escuelas de Libia desde su publicación. Para Diederik Vandewalle, "mucho de él (del Libro Verde) es bastante complicado; no es un

3 Billones anglosajones equivalentes a mil millones $\left(10^{9}\right)$ de dólares.

4 Resoluciones del Consejo de Seguridad de las Naciones Unidas Nos. 731, 748 y 883. 
libro tanto como [sí] una colección de aforismos (...) es pura ideología casera” (Larson, 2011). El texto está dividido en tres tomos que abordan los siguientes aspectos.

\section{Tomo uno - La solución al problema de la democracia [es] la autoridad del pueblo}

En este tomo se hace una abierta crítica al sistema democrático representativo occidental. Se definen los parlamentos como "una distorsión del pueblo" y una "falsa solución al problema de la democracia". Los partidos políticos y las clases sociales se conciben como una "forma contemporánea de dictadura", pues implican el gobierno de una parte de la población sobre todos los demás. Para Gadafi, la solución a las deficiencias del modelo democrático occidental consiste en el establecimiento de "asambleas populares y comités del pueblo", que permitan el ejercicio de la democracia directa, en clara oposición a los mecanismos representativos que, según él, "se aislaban de las masas y les impedían dirigir sus asuntos políticos".

\section{Tomo dos - La solución al problema económico [es] el socialismo}

Según Gadafi, a pesar de los "nada despreciables" avances en la historia de la economía, continúan irresolutos los problemas derivados "del trabajo y los salarios, la relación entre los productores y los propietarios”, así como la de los "los trabajadores y los empresarios". La solución al problema económico es, entonces, "abolir el sistema asalariado, emancipando al pueblo de esta esclavitud y regresando a las leyes naturales que definían las relaciones antes de que emergieran las clases, las formas de gobierno y las leyes artificiales". Solo a través de este ejercicio es factible establecer un sistema de propiedad pública que beneficie a toda la sociedad, en reemplazo de un sistema de propiedad privada que solo beneficia a propietarios.

\section{Tomo tres - Bases sociales de la Tercera Teoría Universal}

Se exalta profundamente al nacionalismo como el elemento cohesionador de los diferentes grupos sociales que conforman una nación. Según el autor, 
"las naciones cuyo nacionalismo es destruido están sujetas a la destrucción". Igualmente, se establece una narrativa alrededor de los "movimientos de liberación nacional", que buscan eliminar la dominación de la que son objeto por parte de otro grupo humano (en clara referencia al colonialismo). De la misma forma, el tomo aborda la politización y visión filosófica de Gadafi respecto a temas como la familia, la tribu, la nación, la mujer, las minorías, la educación, la música, el arte, el deporte, la equitación y el escenario. Además, se argumenta que el pueblo negro predominará en el mundo, pues la esclavitud sufrida a mano de "los blancos" se constituye como "una motivación psicológica de venganza y triunfo que no puede ser ignorada”. La Tercera Teoría Universal es presentada como la alternativa a la invalidez de los modelos capitalista y comunista.

\section{Antecedentes inmediatos a las hostilidades - La Primavera Árabe y el "día de la ira”}

“¿Cómo esperan que me gane la vida?”, estas fueron las últimas palabras de Mohamed Bouazizi, un vendedor ambulante tunecino que pasó a la historia como la chispa que desató la protesta social más grande conocida en la región del Magreb, norte de África y la Península Arábiga (Alizadeh, 2012).

Bouazizi se prende fuego a sí mismo el 17 de diciembre de 2010, en un acto de desesperación después de que su carreta y sus productos fueran confiscados por la Policía de Sidi Bouzid, en Túnez. Rápidamente, el acto se convierte en el símbolo de rebeldía necesario para inspirar las protestas y el clamor de libertad en 18 países del Mundo Árabe. ${ }^{5}$

Las manifestaciones empezaron en Libia, entre el 13 y el 16 de enero de 2011, teniendo como pretexto la tardanza en la entrega de viviendas subsidiadas por el Estado en la ciudad de Darnah. A medida que las manifestaciones aumentaban, Mohammed Hweji, ministro de Industria y Comercio

5 Túnez, Argelia, Mauritania, Sahara Occidental, Arabia Saudí, Omán, Yemen, Libia, Líbano, Kuwait, Sudán Jordania, Siria, Egipto, Irak, Irán, Marruecos y Palestina. 
libio, anunció la inversión de 24 billones $^{6}$ de dólares en soluciones de vivienda, en un evidente intento de sofocar las protestas.

Las redes sociales jugaron un papel fundamental en la coordinación de las protestas en todo el mundo árabe, mientras que para Yemen, Algeria y Baréin las fechas claves para los manifestantes fueron el 3, 12 y 14 de febrero; para Libia, en particular, el "día de la ira" fue programado para el 17 del mismo mes (Cembrero, 2011; Wikstrom, 2011).

Aunque las protestas empezaron desde el 15 de febrero en Bengasi, como resultado del arresto del abogado defensor de derechos humanos Fathi Tarbel, no fue hasta el 17 que la situación se salió de control para la Policía y el Ejército libio. Alentadas por la Conferencia Nacional de la Oposición Libia, una organización política antigadafista nacida en el Reino Unido en 2005, las protestas del 17 de febrero no solo contaban con la motivación de las - ya para ese entonces exitosas - revoluciones egipcia y tunecina, sino que buscaban replicar las protestas contra el régimen llevadas a cabo en la misma fecha, 5 años atrás (Asharq $\mathrm{Al}$-awsat, 2011).

El trágico saldo del 17 de febrero fue cubierto por diferentes medios de comunicación sin lograr un consenso en el número de muertes, que se estiman en alrededor de 15 solo en Bengasi (BBC News, 2011). Otros medios de comunicación reportaron hechos tan graves como manifestantes siendo atacados por francotiradores y desde helicópteros (London Evening Standard, 2011).

Además de la ya bastante crítica situación en Bengasi, las manifestaciones se extendieron rápidamente en la región nororiental de Libia sobre las ciudades de Ajdabiya, Derna, y Al Bayda. En Trípoli y Zintan, al noroccidente del país, también se presentaron graves manifestaciones que terminaron con la muerte de al menos 61 personas tres días después (Fadel, 2011).

Lo que inicialmente fue difundido en redes sociales y medios de comunicación como "día de la ira", pasaría a integrar el episodio de la guerra civil ahora conocido como la "Primera Batalla de Bengasi". 7 El primer enfrentamiento de las fuerzas de seguridad libias en contra de manifestantes y unidades militares que desertaron del Ejército (Kessler, 2011). A partir del 17 de febrero

6 Billones anglosajones equivalentes a mil millones $\left(10^{9}\right)$ de dólares.

7 Que, se considera, duró desde el 15 hasta el 20 de febrero de 2011. 
y hasta la caída de Gadafi, el empleo sistemático de la violencia indiscriminada en contra de la población civil e insurgentes sería una constante.

\section{Actores e intereses involucrados en el conflicto armado}

Como cualquier otro conflicto, la guerra civil libia enfrentó a dos bandos de visiones políticas e ideológicas diametralmente opuestas. Por una parte, el Estado, representado por el Gobierno de la Gran Yamahiriya Árabe Libia Popular Socialista en cabeza del Hermano Líder y Guía de la Revolución, Muamar Gadafi. El líder libio contaba con apoyo de sus fuerzas militares oficiales, fuerzas paramilitares, algunas tribus y mercenarios internacionales. Igualmente, recibió apoyo militar tanto de Zimbabue como de Bielorrusia.

En el otro lado del espectro, y con la firme convicción de derrocar al régimen, se encontraba el Consejo Nacional de Transición (en adelante CNT), una organización político-militar que lideraba los esfuerzos para convertir a Libia en una democracia participativa. El CNT fue apoyado por el Ejército Nacional de Liberación, el Grupo Islámico Combatiente Libio, tribus antigadafistas y supuestos mercenarios internacionales. De la misma forma, recibió apoyo directo de Catar, Jordania, Suecia, Emiratos Árabes Unidos y Marruecos. Otros países como, Estados Unidos, Reino Unido, Canadá y Francia participaron dentro de la estructura militar combinada ya presente dentro de la OTAN.

\section{Fuerzas pro-Gadafi}

\section{Entidades de Gobierno}

Muchas de las organizaciones, ministerios y agencias del Gobierno libio no estaban concebidas para luchar en contra de la insurrección popular, pero fueron instrumentalizadas para hacerlo. Para Ian Roxborough (2007), la contrainsurgencia tiene éxito al crear los medios organizacionales para el control político de la población. Según su visión, los estrategas militares han interpretado esto, equivocadamente, como "algo que debe hacer alguien más", cuando en realidad el control de la población es complementario al esfuerzo 
militar. Por lo tanto, al ser la contrainsurgencia un esfuerzo de Estado, esta se lleva a cabo a través de muchos más mecanismos que la simple aplicación del poder militar. Como ejemplo de lo anterior, numerosos medios de comunicación y académicos han indicado que con el ánimo de controlar las protestas, el Gobierno libio suspendió sistemática y deliberadamente los servicios de agua, energía e internet (Dainotti et al., 2011; Faraon et al., 2011; Shavitt \& Zilberman, 2012).

\section{Fuerzas Militares}

Como se mencionó anteriormente, Libia fue el segundo comprador de armas más importante del mundo después de Irán, 75\% de las cuales fueron adquiridas a la Unión Soviética y posteriormente a Rusia. A pesar de tener unas fuerzas militares relativamente poco numerosas ${ }^{8} \mathrm{y}$ un presupuesto de defensa estimado en 800 millones de dólares, el equipo y tecnología militares con que contaba Libia antes de la guerra no eran, en absoluto, los esperados para un país en desarrollo. En 2010, las fuerzas militares libias fueron estimadas en 76.000 miembros, de los cuales 50.000 conformaban el Ejército (con 25.000 conscriptos), 8000 la marina y 18.000 la fuerza aérea (International Institute for Strategic Studies, 2010a). Dentro del equipamiento del Ejército cabe resaltar la increíble cantidad de 2205 tanques y más de 1000 vehículos de combate de infantería; 945 vehículos de transporte blindados, 2296 piezas de artillería (incluyendo 45 misilísticas), más de 3000 misiles antitanque y 914 sistemas de defensa antiaérea (424 misilísticos). La marina (incluyendo la guardia costera), contaba en 2010 con 2 fragatas y una corbeta como principales plataformas de superficie, 2 submarinos clase Foxtrot, ${ }^{10} 12$ embarcaciones de apoyo y soporte, además de 4 buques antiminas. La fuerza aérea contaba con la significativa cantidad de 374 aeronaves de combate entre las que se destacan 7 bombarderos supersónicos, 229 cazas (fighters) y 113 aviones de ataque a tierra (fighter

8 Para una población estimada de 6.461 .454 en 2010 (Central Intelligence Agency, 2011), 76.000 efectivos equivalen a un soldado cada 850 habitantes, en comparación con el caso colombiano del mismo año, que se estimaba en un soldado por cada 156 habitantes.

9 Un país como Brasil, considerado una potencia económica regional en América del Sur, apenas contaba el mismo año con 219 tanques, a pesar de tener unas fuerzas militares de 327.720 efectivos y un presupuesto de 29.7 billones de dólares (International Institute for Strategic Studies, 2010b).

10 Producidos por la Unión Soviética desde 1958 bajo el nombre de Projecto 641. 
ground attack). Adicionalmente, se contaba con 35 helicópteros de ataque y 85 helicópteros de transporte. ${ }^{11}$

\section{Fuerzas paramilitares}

Aunque no hay datos concretos de la fecha en que se estableció la Guardia Revolucionaria (al-Haras al-thawri), su fundación está profundamente asociada a los Comités Revolucionarios, organismos a través de los cuales Gadafi pretendió instaurar un modelo de democracia directa. Desde principios de la década de 1980, los mismos comités fueron formados dentro de las fuerzas militares con la finalidad de llevar a cabo el adoctrinamiento ideológico y tareas asociadas a la seguridad (contrainteligencia). Se consideraban una fuerza élite con personal especialmente escogido que totalizaba entre $2000 \mathrm{y}$ 3000 efectivos (Hunter, 1991; Mattes, 2004).

\section{Mercenarios internacionales}

Es difícil estimar la cantidad de mercenarios que participaron en la guerra civil libia, a pesar de que su presencia fue evidente. Muchos de ellos, menores de edad que ni siquiera hablaban árabe, fueron capturados por tropas antigadafistas confesando sus identidades, países de origen, modo de reclutamiento, salario prometido, etc. Los países de origen de dichos combatientes fueron principalmente Chad, Túnez, Marruecos, República Democrática del Congo, Níger, Mali y Sudán, además de combatientes de tribus tuaregs a lo largo del Sahara. De la misma forma, se afirma que participaron "mercenarios blancos" provenientes de Europa (serbios y bosnios veteranos de la Guerra de Kosovo), Asia e incluso Sudáfrica (Makariusová \& Ludvík, 2012; Smith, 2011).

\section{Apoyo internacional}

Gadafi recibió amplio apoyo principalmente de Zimbabue y Bielorrusia. Robert Mugabe, el famoso líder marxista zimbabuense aún en el poder en 2011, envió "varios cientos" de militares entre los que se destacan fuerzas espe-

11 Para contextualizar la capacidad aérea libia en 2010, cabe mencionar que en ese momento la Fuerza Aérea Colombiana contaba con 90 aviones en total (31 de combate) y 112 helicópteros, de los cuales 26 eran de ataque y 71 de transporte o utilitarios (International Institute for Strategic Studies, 2010b). 
ciales y la denominada 'Quinta Brigada'. Esta última, entrenada originalmente en Corea del Norte, es ampliamente conocida por haber participado en el Gukurahundi, una serie de masacres que buscaban el exterminio de la Unión Popular Africana de Zimbabue (ZAPU) y que dejó como saldo un estimado de 20.000 a 30.000 civiles muertos entre 1982 y 1986. El apoyo bielorruso fue, por su parte, mucho más subrepticio, pues no contó con la participación abierta de unidades militares, sino que se utilizó la figura de "asesores militares". Bajo esta denominación, un contingente de no menos de 500 especialistas asesoró al Gobierno libio, entre los que cabe resaltar la presencia de operadores Spetsnaz GRU, versión bielorrusa de fuerzas especiales soviéticas/rusas bajo el control del Directorio Principal de Inteligencia (Главное разведывательное управление). Los Spetsnaz bielorrusos participaron en la guerra afgano-soviética (1978-1992) y en el conflicto Nagorno Karabaj (1988-1994). En 2018, Vyacheslav Kachura, antiguo comandante del Escuadrón 334 de Fuerzas Especiales, fue el último bielorruso retenido por las milicias antigadafistas que recuperó la libertad, gracias, en parte, a las gestiones adelantadas por Rusia (Eppel, 2006; Komsomolskaya Pravda, 2011; Ngwenya, 2017; Radov, 2011; RIA Novosti, 2018).

\section{Fuerzas anti-Gadafi}

\section{Consejo Nacional de Transición (CNT)}

El 21 de febrero de 2011, apenas unos días después del "día de la ira", se crea en Bengasi el CNT como máximo órgano de la revolución libia. El CNT se define a sí mismo desde su creación como la "cara política de la revolución" y, una semana después, como el único cuerpo representante del pueblo de Libia y del Estado libio (Joyce \& Wain, 2014, p. 20; Warbrick, 2012). Como órgano máximo, el CNT no solo lideraba los esfuerzos políticos por derrocar al régimen, sino que aglomeraba los esfuerzos de varias organizaciones de carácter militar que se citan a continuación.

\section{Ejército Nacional de Liberación}

También conocido como Ejército Libre Libio, fue la organización militar constituida por militares desertores del Ejército regular y voluntarios bajo el 
mando del Mayor General Abdul Fatah Younis Al-Obeidi, considerado el segundo hombre más importante del régimen durante el periodo gadafista (Claiborne, 2011). Aunque no hay claridad respecto a su cantidad de efectivos, Fawzi Abdelali, ministro del Interior libio, tras la guerra informó acerca de la creación de un "comité de excombatientes" para la reintegración de 200.000 hombres que lucharon durante el conflicto, de los cuales 50.000 pasarían a integrar las fuerzas de seguridad. ${ }^{12}$

\section{Grupo Islámico Combatiente Libio o Libyan Islamic Fighting Group (LIFG)}

El LIFG nace después de la guerra de Afganistán como organización aglutinadora de los combatientes libios que lucharon contra la Unión Soviética entre 1978 y 1992. Muchos de los combatientes del LIFG eran musulmanes radicales y buscaban desde finales del siglo XXI la instauración del 'Califato Islámico’ en Libia, luchando infructuosamente contra el régimen. Se estima que cuando iniciaron las protestas en Bengasi, 850 combatientes del LIFG se encontraban ya en la ciudad (Moniz, 2017). A la organización también se le atribuye (en alianza con el MI6) la coordinación de un atentado fallido para asesinar a Gadafi en 1996 (Bright, 2002). La presencia del LIFG en la guerra civil libia es ampliamente cuestionada, pues a pesar de subordinarse al CNT, la organización había jurado lealtad a Al-Qaeda desde 2007. Con la adopción de las resoluciones del Consejo de Seguridad de las Naciones Unidas 1267 (1999), 1373 (2001) y 1540 (2004) la comunidad internacional no solo había designado terroristas a los talibanes y sus organizaciones asociadas, sino que buscaba combatirlas y prevenir su acceso a armas de destrucción masiva. En consecuencia, a pesar de anunciar su separación de Al-Qaeda en 2009 (Blair, 2009) el LIFG fue designado como organización terrorista por los Estados Unidos desde 2004 hasta 2015 (U. S. Department of State, 2020).

12 Aunque el ministro Fawzi Abdelali manifestó el proceso de reintegración de 200.000 combatientes, es necesario considerar que tal cantidad no hacía parte del Ejército Nacional de Liberación desde el comienzo de la guerra. Muchos de ellos, que empezaron luchando a favor de Gadafi, paulatinamente desertarían para unirse a las tropas "libres" bajo el mando del CNT. 


\section{Tribus anti-gadafistas}

Una de las consideraciones demográficas más complejas de la guerra civil libia es su heterogeneidad tribal. Una seria identidad nacional habría puesto en riesgo el control de Gadafi sobre la sociedad, por lo que mantener su división en pequeñas facciones hacía mucho más sencillo su control y represión (Hweio, 2012). El líder se aseguró de entregarle a los miembros más leales de su propia tribu (Qadadifah) importantes cargos dentro del Gobierno, las fuerzas de seguridad y organismos de inteligencia, con el fin de asegurar la estabilidad de su régimen y su propia integridad (Mokhefi, 2011). El historiador Faraj Abd al-Aziz Najm identificó 140 tribus y clanes en Libia, de los cuales considera que aproximadamente $30^{13}$ desarrollan una influencia visible y genuina (Faraj, 2005, como se cita en Ladjal, 2016). No fue una casualidad que la revolución empezara al oriente del país donde residen las tribus más marginalizadas por el régimen. Lugares donde la inversión social era escasa y la represión tal, que se llegó al extremo de de prohibir a las tribus comunicarse en sus propios dialectos (Von Rohr, 2011).

\section{Mercenarios internacionales}

El 23 de agosto de 2011, Muhammad Gadafi, hijo mayor del líder libio, manifestó desde Trípoli que estaba luchando "en contra de las tropas de la OTAN y mercenarios [...] no hay rebeldes libios aqui"” (Interfax, 2011). Aunque Estados Unidos y el Reino Unido estuvieron involucrados activamente en el apoyo a los rebeldes, oficialmente ambos gobiernos negaron el apoyo a empresas privadas de seguridad. A pesar de ello, operadores de fuerzas especiales y de inteligencia occidentales, aparentemente británicos, fueron filmados apoyando a los rebeldes en el frente de batalla en Misurata (Borger \& Chulov, 2011). Debido al escándalo, el ministro de Relaciones Exteriores británico William Hague finalmente confirmó que solamente "10 asesores" militares habrían sido enviados a Bengasi, y que los operadores de fuerzas especiales del

13 Alawana-Souk El Joma’a, Al-Mahameed, Warfalla, Tarhona, Misurata, Al-Jawary, Siyan, Warshfana, Zawia, Ghryan, AL-Asabea, Al-Fwatir, Awlad Busayf, Al-jbalya, Zwara, Alajelat, Al-Nawael, Alalqa, Al-Rijban, al Mashashi, Amaym, Aj-Jwazy, Al-Awagir, Magharba, Al-Abaydat, Drasa, Al-Barasa, Al-Fawakhir, Zuwayya, Majabra, Awama, Minfa, Taraki, Shwàir, Toubou, Awlad-Suleiman, Qadhadhfa, Al-Hosoon, Ferrjan, Al-Riyyah, Magarha, Al-Zuwaid, Al-Hutman, Al-Hassawna, Tuareg. 
Reino Unido presentes en Libia habían sido contratados a través de empresas privadas por el Gobierno catarí (Norton-Taylor \& Stephen, 2011). Gracias a los correos filtrados por WikiLeaks en 2012, se sabe que los Estados Unidos contrataron los servicios de James F. Smith, antiguo director de Blackwater, quizá la empresa de mercenarios más famosa del mundo. En 2011, Smith había fundado ya SCG International, otra empresa similar con experiencia en los conflictos de Afganistán e Irak. Tal fue su rol dentro del conflicto, que se le atribuye incluso su participación en la muerte del propio Gadafi (Al-Saadi, 2012). Pierre Marziali, exmilitar y presidente de la compañía de seguridad privada francesa Secopex fue herido de muerte en Bengasi mientras "discutía oportunidades de negocios con los oponentes del coronel Muamar Gadafi”. Bernard Valero, portavoz del Ministerio de Relaciones Exteriores francés, se refirió superficialmente a los hechos sin dar ningún detalle de las actividades de Marziali en Libia. El general rebelde Ahmed al-Ghatrani, atribuyó la muerte del mercenario a "pandillas que el antiguo régimen utilizaba" (Fahim \& Baume, 2011).

\section{Comunidad internacional}

El uso indiscriminado de la violencia en contra de los manifestantes fue condenado de inmediato tanto por países como por órganos supranacionales. Jean Ping, presidente de la Comisión de la Unión Africana, anunció su preocupación por la situación en Libia y su interés por detener el derramamiento de sangre.

En marzo de 2011, tras rechazar la intervención occidental en el continente, este mismo órgano crearía un panel compuesto por representantes de Sudáfrica, Uganda, Mauritania, Congo y Mali, con el fin de mediar entre las partes y buscar solucionar la crisis. Ramtane Lamamra, comisario de Paz y Seguridad de la Unión Africana, afirmó que Libia necesitaba una "urgente acción africana" con el fin de cesar las hostilidades, clara manifestación de que el continente se oponía a la intervención externa. Amr Moussa, secretario general de la Liga Árabe, manifestó abiertamente su preocupación por la situación y, tras condenar la violencia en contra de los manifestantes, suspendió la participación de Libia en las reuniones del consejo.

Por último, tras escalar la violencia, la Liga Árabe apoyó la imposición de la zona de exclusión aérea bajo la excusa de evitar que Gadafi atacara con aero- 
naves militares a la población civil (Galal, 2011). En una declaración oficial emitida el 20 de febrero de 2011, Catherine Ashton, alta representante para Asuntos Exteriores y Política de Seguridad de la Unión Europea, manifestó que el órgano "está extremadamente preocupado por los eventos desarrollándose en Libia y las muertes reportadas de un gran número de manifestantes”. De la misma manera, la Unión Europea (UE) instó a las autoridades libias a cesar los bloqueos a la telefonía y a los servicios de internet, a permitir el trabajo de los medios de comunicación a lo largo del país y a garantizar el derecho a la libre expresión y asociación de los manifestantes (Ashton, 2011).

Tras una votación unánime el Consejo de Seguridad de las Naciones Unidas emitió las resoluciones 1970 y 1973 que buscaban, además de la imposición de sanciones, el establecimiento de la zona de exclusión aérea que servirá de base posteriormente para la subsiguiente intervención militar. ${ }^{14}$ Durante su pico más alto, la coalición internacional contó con 8000 tropas de 16 países, comprometidas con 21 embarcaciones $^{15}$ y 260 aeronaves distribuidas ${ }^{16}$ en 14 bases a lo largo del mar Mediterráneo (OTAN, 2011b).

\section{Papel de las Naciones Unidas en el conflicto}

En la Cumbre Mundial de 2005, la responsabilidad de proteger se convirtió en un compromiso global con el fin de evitar el genocidio, los crímenes de guerra, la depuración étnica y los crímenes de lesa humanidad. Este compromiso tiene tres aproximaciones fundamentales: la obligación del Estado frente a la protección de su propia población, la obligación de la comu-

14 El involucramiento de la OTAN implica que, al menos indirectamente, los 28 estados miembros a 2011 participaron de alguna manera en la aplicación de la resolución 1973. Sin embargo, 14 países participaron directamente en las hostilidades con el despliegue de unidades militares (principalmente navales y aéreas) que se hicieron visibles a lo largo del Mediterráneo. Estos fueron: Bélgica, Bulgaria, Canadá, Dinamarca, Francia, Grecia, Italia, Países Bajos, Noruega, Rumania, España, Turquía, Reino Unido y los Estados Unidos de América. Otros países no miembros de la OTAN, como Jordania, Catar, Suecia y Emiratos Árabes Unidos, igualmente participaron activamente en el derrocamiento del régimen gadafista a través del suministro de apoyo militar o logístico.

15 Fragatas, destructores, submarinos (incluyendo nucleares), buques de suministro, embarcaciones de asalto anfibio y portaaviones. de ataque.

16 Aviones caza, de vigilancia y reconocimiento, tanqueros aire-aire, no tripulados y helicópteros 
nidad internacional de ayudar a Estados que no pueden brindar dicha protección, y la obligación de la comunidad internacional de proteger poblaciones cuyos Estados no pueden hacerlo.

La represión violenta de las manifestaciones que comenzó —al menos abiertamente — el "día de la ira", tuvo un fuerte impacto en la Organización de las Naciones Unidas (ONU) y, particularmente, en los compromisos adquiridos con la adopción de la responsabilidad de proteger. Con respecto a las medidas adoptadas por el régimen de Gadafi, el secretario general de las Naciones Unidas, Ban Ki-moon (United Nations, 2011a), afirmó que:

Las acciones tomadas por el régimen en Libia son una clara violación a todas las normas que gobiernan el comportamiento internacional y son serias transgresiones a derechos humanos y al derecho internacional humanitario. Son inaceptables. Es de gran importancia que el consejo (de Seguridad) en respuesta haya alcanzado un consenso y esté determinado a respetar sus responsabilidades para el mantenimiento de la paz y la seguridad internacional. ${ }^{17}$ (s. p., la traducción es mía)

A pesar de que la guerra civil libia fue atizada por un sinnúmero de factores sociales y políticos acumulados a lo largo de la dictadura, la intervención internacional fue, sin duda, el catalizador de la violencia sistemática y organizada que se traduciría en una guerra propiamente dicha desde la visión clausewitziana.

Para mantener la paz y la seguridad internacionales, en un sistema donde no todos los países enmarcan su política exterior homogéneamente, es fundamental que la legitimación de la coerción internacional se exprese formalmente en resoluciones ${ }^{18}$ emitidas por el Consejo de Seguridad de la ONU. ${ }^{19}$

17 Texto original: "The actions taken by the regime in Libya are clear cut violations of all norms governing international behavior and serious transgressions of international human rights and humanitarian law. They are unacceptable. It is of great importance that the Council in response has reached the consensus and is determined to uphold its responsibilities for the maintenance of international peace and security".

18 No siendo el único modo de concluir las reuniones del Consejo de Seguridad, pues estas podrían culminar sin acción, con un comunicado, con una declaración de la presidencia o con la aprobación de una resolución.

19 En 2011, compuesto por los cinco miembros permanentes (China, Francia, Rusia, Reino Unido y los Estados Unidos de América) y diez no permanentes (Alemania, Bosnia y Herzegovina, Brasil, Colombia, Gabón, India, Líbano, Nigeria, Portugal y Sudáfrica). 
Para el caso particular de la crisis libia, se emitieron dos resoluciones que buscaron, inicialmente, limitar el poder económico del régimen y establecer un embargo de armas; a lo que se sumaría, posteriormente, la imposición de una zona de exclusión aérea para la protección de la población civil.

\section{Resolución 1970 del Consejo de Seguridad de las Naciones Unidas}

La resolución se emite el 26 de febrero de 2011 tras la reunión número 6491 del Consejo de Seguridad — como respuesta inicial a la represión en contra de los manifestantes - y cubre, en términos generales, los siguientes aspectos (UN Security Council, 2011a):

1. Aplaude la condena de las atrocidades perpetradas por las fuerzas de seguridad libias por parte de la Unión Africana y la Liga Árabe.

2. Expresa su preocupación por la violación sistemática de los derechos humanos, la represión a los manifestantes y los crímenes de lesa humanidad perpetrados por el régimen libio.

3. Acoge positivamente la resolución A/HRC/S-15/2 del 25 de febrero de 2011, emitida por el Consejo de Derechos Humanos, a través de la cual se ordena la confirmación de una comisión internacional independiente para investigar las violaciones al Derecho Internacional Humanitario en Libia.

4. Recuerda el artículo 16 del Estatuto de Roma, según el cual el Consejo de Seguridad de la ONU puede pedir el no inicio o suspensión de una investigación hasta por doce meses, por parte de la Corte Penal Internacional, y refiere el caso de Libia al fiscal jefe de dicho órgano.

5. En concordancia con el artículo 41 del capítulo VII de la Carta de las Naciones Unidas, el Consejo de Seguridad exhortó a:

a. Respetar los Derechos Humanos y el Derecho Internacional Humanitario por parte de autoridades libias.

b. Permitir el acceso a territorio libio de observadores de derechos humanos. 
c. Asegurar la seguridad de extranjeros, sus bienes, y facilitarles la salida del país si así lo quisieran.

d. Asegurar la entrada de ayudas médicas y humanitarias, así como de trabajadores humanitarios.

e. Levantar todas las prohibiciones impuestas a los medios de comunicación.

f. Ordena el embargo de cualquier clase de armamento y repuestos militares para aeronaves, vehículos o embarcaciones libias, así como armamento tradicional y municiones de cualquier tipo. El embargo se extiende a la asistencia técnica, entrenamiento, financiamiento, mantenimiento y cualquier otro apoyo de naturaleza militar, incluyendo la contratación de mercenarios.

g. Prohíbe la exportación de armas por parte de Libia. Igualmente, la adquisición de dicho material por cualquier otro país a través de nacionales, embarcaciones o aeronaves con bandera o matrícula libias.

h. Se emite la prohibición de viajar para 16 representantes $^{20}$ del régimen libio (incluyendo al propio Gadafi) e insta a los Estados miembros a evitar la entrada o tránsito del personal a través de sus territorios.

20 Al-Baghdadi, Dr. Abdulqader Mohammed; jefe de la Oficina de Enlace de los Comités Revolucionarios. Dibri, Abdulqader Yusef; jefe de la seguridad personal de Muammar Qadhafi y responsabilidad en la seguridad del régimen. Dorda, Abu Zayd Umar; director de la Organización de Seguridad Externa y jefe del organismo de inteligencia externa. Jabir, General de División Abu Bakr Yunis; ministro de Defensa y responsabilidad general en las acciones de las Fuerzas Armadas. Matuq, Matuq Mohammed; secretario de servicios públicos. Qadhaf Al-dam, Sayyid Mohammed; primo de Muamar Gadafi. Qadhafi, Aisha Muammar; hija de Muamar Gadafi. Qadhafi, Hannibal Muammar; hijo de Muamar Gadafi. Qadhafi, Khamis Muammar; hijo de Muamar Gadafi, comandante de unidades militares acusadas de represión contra manifestantes. Qadhafi, Mohammed Muammar; hijo de Muamar Gadafi. Qadhafi, Muammar Mohammed Abu Minyar; Líder de la Revolución, Comandante Supremo de las Fuerzas Armadas y responsable de ordenar la represión de manifestantes, acusado de violación de derechos humanos. Qadhafi, Mutassim; hijo de Muamar Gadafi, consejero de seguridad nacional. Qadhafi, Saadi; hijo de Muamar Gadafi, comandante de las fuerzas especiales, comandante de unidades militares acusadas de represión contra manifestantes. Qadhafi, Saif al-Arab; hijo de Muamar Gadafi. Qadhafi, Saif al-Islam; hijo de Muamar Gadafi, director de la Fundación Gadafi. Abdullah Al-Senussi, coronel Abdullah, jefe de la inteligencia militar. Condenado in absentia por el atentado perpetrado contra el vuelo de UTA (1989). 
i. Congelamiento de de cualquier clase de activos y recursos económicos administrados directa o indirectamente por 6 individuos $^{21}$ específicos asociados a Gadafi.

\section{Resolución 1973 del Consejo de Seguridad de las Naciones Unidas}

El 17 de marzo de 2011, tras la culminación de la reunión, el Consejo de Seguridad aprueba la resolución 1973 con diez votos a favor, cero en contra y cinco abstenciones. ${ }^{22}$ La resolución fue propuesta por Líbano, Francia y Reino Unido, contando con el apoyo de los Estados Unidos. Tan pronto la resolución fue aprobada, François Baroin, representante del Gobierno francés, anunció que "los ataques [contra las fuerzas de Gadafi] empezarán rápidamente". El secretario general de la ONU indicó, por su parte, que "dada la crítica situación sobre el terreno, espero acción inmediata sobre las disposiciones de la resolución" (Naciones Unidas, 2011b).

Los países que se abstuvieron de votar a favor o en contra manifestaron serias preocupaciones con la aplicación de la resolución 1973. Vitaly Churkin, representante de la Federación Rusa, manifestó que muchas de las preguntas relacionadas con las disposiciones de la resolución quedaron sin respuesta, como, por ejemplo, el cómo y por quiénes las medidas debían ser implementadas, así como cuál sería el alcance de las mismas. China se negó a votar en contra teniendo "en consideración los deseos de la Liga Árabe y la Unión Africana” (UN Security Council, 2011c).

Peter Wittig, embajador de Alemania ante la ONU, expresó que, si bien la intención del Consejo de Seguridad era frenar la violencia en Libia, era preferible endurecer las sanciones ya impuestas mediante la resolución 1970 que la implementación de una solución militar. Para él, Alemania vio grandes riesgos en la implementación de la resolución 1973, incluyendo la posibilidad de una gran pérdida de vidas que no debería ser subestimada. En efecto, la

21 Qadhafi, Aisha Muammar; Qadhafi, Hannibal Muammar; Qadhafi, Khamis Muammar; Qadhafi, Muammar Mohammed Abu Minyar; Qadhafi, Mutassim y Qadhafi, Saif al-Islam.

22 A favor: Bosnia y Herzegovina, Colombia, Francia, Gabón, Líbano, Nigeria, Portugal, Sudáfrica, Reino Unido y Estados Unidos de América. Abstenciones: Alemania, Brasil, China, India y Rusia. 
determinación de tomar acciones militares podría desencadenar un conflicto mucho más prolongado que, a su vez, podría extenderse por el norte de África (UN Security Council, 2011c).

La resolución 1973 estableció la base legal para la intervención militar en Libia y dejó en claro las siguientes determinaciones (UN Security Council, 2011b):

1. Condenar nuevamente las graves violaciones a los Derechos Humanos y el Derecho Internacional Humanitario por parte del régimen libio y recordar las medidas adoptadas a través de la resolución 1970.

2. Tomar en consideración la preocupación de otros órganos supranacionales como el Consejo de Paz y Seguridad de la Unión Africana, el Consejo de la Liga de los Estados Árabes y la Organización de la Conferencia Islámica quienes no solo condenaron los hechos de violencia, sino que pidieron la imposición de una zona de exclusión aérea para proteger a la población civil de bombardeos.

3. Reiterar la decisión de remitir el caso libio a la Corte Penal Internacional con el fin de castigar a los responsables por los ataques en contra de la población civil.

4. Deplorar el uso de mercenarios por parte del régimen libio.

5. En concordancia con el artículo 41 del capítulo VII de la Carta de las Naciones Unidas, el Consejo de Seguridad:

a. Exige a las autoridades libias el cese al fuego y el respeto por el derecho internacional incluyendo el derecho internacional humanitario, las normas de los derechos humanos y el derecho de los refugiados.

b. Autoriza a los Estados Miembros a que,

actuando a título nacional o por conducto de organizaciones o acuerdos regionales y en cooperación con el Secretario General, adopten todas las medidas necesarias [...] para proteger a los civiles y las zonas pobladas por civiles que estén bajo amenaza de ataque en la Jamahiriya Árabe Libia, incluida Benghazi, aunque excluyendo el uso de una fuerza de ocupación extranjera de cualquier clase en cualquier parte del territorio libio. (p. 3$)^{23}$

23 (Cursivas agregadas). Para el posterior desarrollo de la guerra este enunciado es fundamental, pues limitaría la intervención militar, principalmente, a los dominios aéreo y naval. Siendo las consideraciones marítimas importantes para el embargo de armas, la campaña aérea en apoyo a los rebeldes fue vital 
c. Establece una zona de exclusión aérea al norte del país con excepción de los vuelos que tienen una finalidad enteramente humanitaria. De la misma forma, autoriza a los Estados miembros a tomar las medidas necesarias para hacer cumplir esta disposición.

d. Modifica el párrafo 11 de la resolución 1970 (embargo de armas) exhortando a los Estados miembros a inspeccionar en puertos, aeropuertos, embarcaciones y aeronaves de bandera libia en búsqueda de material que haya sido previamente prohibido movilizar.

e. Prohíbe los vuelos desde y hacia Libia indicando que todos los Estados Miembros deben denegar a aeronaves públicas o privadas la autorización de sobrevolar o aterrizar en sus territorios.

f. Extiende el congelamiento de activos a "todos los fondos, otros activos financieros y recursos económicos que se encuentren en sus territorios y que sean de propiedad o estén bajo el control, directo o indirecto, de las autoridades libias".

g. Se crea un "Grupo de expertos' 24 con el fin de analizar la información, recomendar y apoyar las medidas tomadas con respecto al caso libio.

\section{Evolución y desarrollo del conflicto}

La aprobación de la resolución 1973 legitimó la intervención internacional que, bajo la intención de proteger a la población civil, garantizó las medidas a que hubiese lugar siempre y cuando no se recurriera a la ocupación militar del territorio. Varios países con capacidades militares expedicionarias tomaron la iniciativa para imponer la zona de no vuelo de forma coordinada, pero sin establecerse un mando militar unificado. La zona de exclusión aérea

para el derrocamiento del régimen, dada la [supuesta] imposibilidad de desplegar tropas en tierra por parte de la coalición internacional.

24 Conocido en inglés como Panel of experts, fue conformado en 2011 por ocho académicos: Salim Raad, Yousef Alserhan, Simon Dilloway, Theodore Murphy, Giovanna Perri, Oumar Dièye Sidi, Savannah de Tessières y Ahmed Zerhouni. 
fue inicialmente impuesta por Francia, Estados Unidos y Reino Unido desde el 19 de marzo, pero no fue hasta el 31 del mismo mes que la OTAN asumió el mando de las unidades militares y las unificaría bajo un solo esfuerzo denominado Operation Unified Protector (Operación Protector Unificado).

Canadá dio inicio a la Operación Mobile el 25 de febrero como una "misión de evacuación" de ciudadanos canadienses atrapados en territorio libio, posteriormente, durante el mes de marzo, la intervención se convirtió en una operación de combate (Government of Canada, 2013). Para Francia, el despliegue naval y aéreo se denominó inicialmente Operación Harmattan. Por su parte, el Reino Unido denominó el inicio de su intervención militar Operación Ellamy, mientras que los Estados Unidos usaron el nombre de Operación Odyssey Dawn.

Los Estados Unidos determinaron, después de la aprobación de la resolución 1973, que la OTAN era el órgano más adecuado para continuar las acciones militares contra Gadafi. Emplear a la alianza no solo le daría gran influencia, sino que representantes importantes como Ivo Daalder, embajador de Estados Unidos ante la OTAN, afirmaron que solo este órgano contaba con la posibilidad de brindar las instalaciones de comando y control requeridas para una coalición tan amplia como en este caso (Daalder \& Stavridis, 2011). No menos importante eran las relaciones ya existentes de la OTAN con otros socios, especialmente en Oriente Medio, lo que facilita el éxito en la coordinación de esfuerzos con dichas naciones. Finalmente, esta relativamente sencilla intervención en contra de un régimen despótico podría ayudar a la reputación de la OTAN, mancillada por sus intervenciones en Afganistán e Irak. En palabras de un alto funcionario estadounidense, "no hay nada como una guerra oportuna, y esta era una guerra muy oportuna para la OTAN" (Mueller, 2015).

A partir del 31 de marzo de 2011, la OTAN centralizó el control de todas las operaciones militares desarrolladas en Libia en cumplimiento de las resoluciones 1970 y 1973 del Consejo de Seguridad de la ONU. La Operación Protector Unificado abarcó tanto el embargo de armas como el establecimiento de la zona de exclusión aérea, además de las acciones necesarias para proteger a la población civil (OTAN, 2011c).

La interpretación de estas acciones, según la OTAN, implicaba la "conducción de ataques aéreos y navales contra las fuerzas militares involucradas en ataques, o amenazando con atacar civiles libios y áreas pobladas de 
civiles”. El Consejo del Atlántico Norte ${ }^{25}$ llevó a cabo la dirección política de la Operación Protector Unificado mientras que el Cuartel General Supremo de las Potencias Aliadas en Europa ${ }^{26}$ en Mons (Bélgica), implementó militarmente las decisiones del consejo a través de la Fuerza de Tarea Conjunta Nápoles. ${ }^{27}$

El teniente general Charles Bouchard (Canadá) fue el comandante de la Fuerza de Tarea Conjunta Combinada Protector Unificado, bajo su liderazgo, el Comando Marítimo Aliado de la OTAN, en Eastbury (Reino Unido), y el Centro de Operaciones Aéreas Combinadas No. 5, en Poggio Renatico (Italia), llevaron a cabo los esfuerzos militares para imponer el embargo de armas sobre Libia, así como la protección a civiles a través de operaciones ofensivas.

A pesar de que en 2011 el Comando Aéreo Aliado para el Sur de Europa se ubicaba en Izmir (Turquía), gran parte de los medios aéreos fueron movidos desde esta ubicación a bases más cercanas al territorio libio, con el fin de favorecer las operaciones militares. En ningún momento, durante el desarrollo de la Operación Protector Unificado, la OTAN dispuso tropas sobre el territorio libio (otan, 2015).

\section{Febrero y marzo de 2011: la revolución desde el este}

El epicentro de la revolución antigadafista fue Bensgasi, la segunda ciudad más grande de Libia y a partir de la cual los efectos de la Primavera Árabe se extendieron por el territorio nacional, lo que produjo la reacción del régimen. Como se mencionó previamente, las protestas en Bengasi empezaron el 15 de febrero, como respuesta al arresto del abogado y defensor de derechos humanos Fathi Tarbel, pero no fue hasta el 17 del mismo mes que las cosas se salieron de control tras el desarrollo del "día de la ira".

25 En inglés North Atlantic Council (NAC), es el principal órgano de decisión política de la OTAN, creado por el artículo 9 del Tratado del Atlántico Norte: "Las partes establecen, por la presente disposición, un Consejo en el que cada una de ellas estará representada para conocer de las cuestiones relativas a la aplicación del Tratado. El Consejo estará organizado de manera que pueda reunirse rápidamente en cualquier momento. El Consejo establecerá cuantos órganos subsidiarios puedan ser necesarios y, en especial, establecerá inmediatamente un comité de defensa que recomendará las medidas apropiadas para la aplicación de los artículos 3 y 5 " (OTAN, 1949).

26 Supreme Headquarters Allied Powers Europe (SHAPE).

27 La Fuerza de Tarea Conjunta Nápoles, en inglés Joint Task Force Naples (JTF Naples), se define como la "Fuerza de Respuesta de la OTAN". Una unidad "tecnológicamente avanzada y flexible que incluye elementos terrestres, aéreos y marítimos listos para moverse rápidamente a cualquier lugar bajo decisión del Consejo del Atlántico Norte" (Allied Joint Force Command Naples, s. f.). 
Para el 23 de febrero, la cifra de muertos en Bengasi se estimaba en 320 y totalizaba más de 1000 a nivel nacional, muchos de los cuales habían sido asesinados por los mercenarios contratados por Gadafi a lo largo de África (Dziadosz, 2011). Al día siguiente, varios medios de comunicación reportaron que otras ciudades, como Misurata y Tobruk, se encontraban bajo el control de los manifestantes. Febrero termina dejando como saldo la parte nororiental del país en manos de los rebeldes, logrando una rápida expansión de la revolución a través de la costa hacia Trípoli, gracias a la única autopista que cruza el país de oriente a occidente.

Gran parte de la ofensiva inicial de ambos bandos tuvo como escenario la línea costera (ver figura 1). La primera semana de marzo, los rebeldes informaron tener bajo su control Zawiyah y Ras Lanuf, sin embargo, una agresiva contraofensiva del régimen a partir del 6 de marzo implicó un retroceso de los rebeldes hasta Bengasi, tras la pérdida de Rảs Lanuf y Ajdabiya. Los enfrentamientos entre las fuerzas libias y los rebeldes — que ya contaban con el apoyo de la coalición internacional- se conocerían posteriormente como la Batalla de Ajdabiya, que finalizaría con la victoria rebelde el 26 de marzo de 2011.

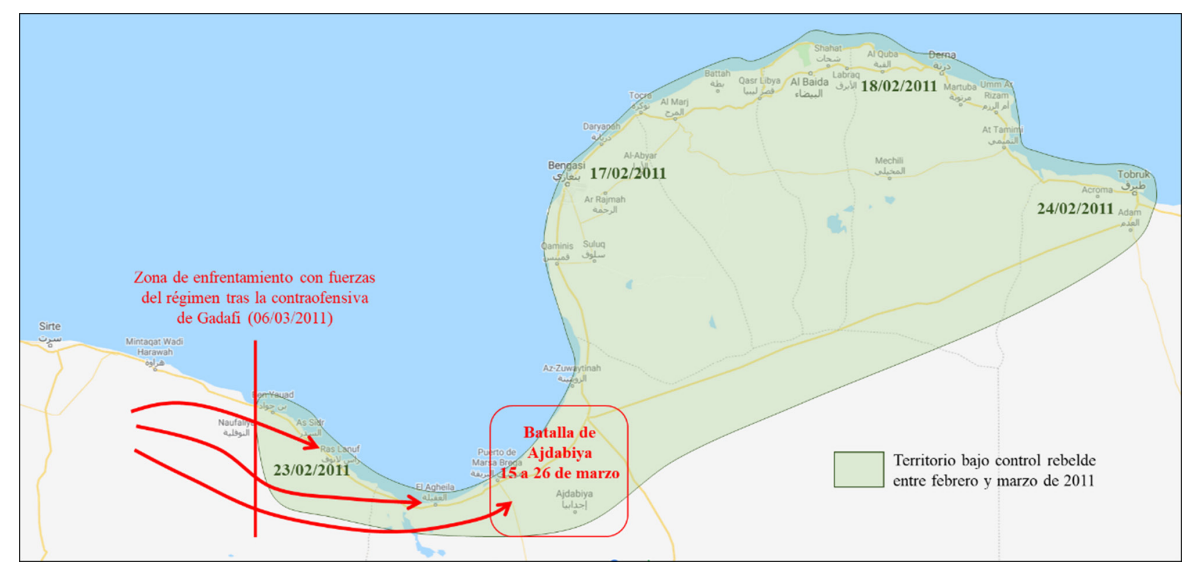

Nota: se observa la expansión de la influencia rebelde a lo largo de la línea costera a partir de la ciudad de Bengasi. Igualmente, se aprecia la zona de enfrentamiento con las fuerzas del régimen libio a la altura de Ben Yauad y la Primera Batalla de Ajdabiya.

Figura 1. Frente oriental de la guerra civil libia (2011) 
La contraofensiva del régimen retomó gran parte del territorio que se encontraba inicialmente bajo el control rebelde, llegando a ocupar parte de Bengasi. Finalmente, cuando la coalición internacional se involucró de lleno a partir del 19 de marzo, tras la expedición de la resolución 1973, las fuerzas del régimen fueron expulsadas de la ciudad y se posicionaron a 50 kilómetros de esta.

El 28 de marzo, el Vicealmirante Bill Gortney, director del Estado Mayor Conjunto de los Estados Unidos, reportó en una rueda de prensa que hasta ese momento la Operación Odyssey Dawn había llevado a cabo 199 ataques con misiles Tomahawk ${ }^{28}$ (ver figura 2), 192 de ellos lanzados por los Estados Unidos. Adicionalmente, reportó 1602 incursiones aéreas, ${ }^{29}$ de las cuales 983 correspondían a misiones desarrolladas por aeronaves estadounidenses, mientras que las restantes 619 a otros países de la coalición. De las 1602 incursiones, 735 correspondían a ataques aéreos de los cuales Estados Unidos llevó a cabo el 50\%. Como resultado de estas acciones, la fuerza aérea libia, así como sus defensas aéreas, habían sido destruidas y solo algunos misiles tácticos tierra-aire restantes presentaban una "modesta amenaza" (U. S. Department of Defense, 2011).

Con el éxito rebelde tras la Batalla de Ajdabiya y el apoyo internacional recibido, las fuerzas antigadafistas lanzaron la Primera Ofensiva del Golfo de Sidra, que cerraría el mes con la retirada de las fuerzas del régimen a lo largo de la línea costera hasta Sirte, ciudad natal de Gadafi (Youssef, 2011).

28 Tomahawk Land Attack Missile (TLAM).

29 Conocidas en inglés como sorties, se definen por el Departamento de Defensa de los Estados Unidos como "un vuelo operacional desarrollado por una aeronave" (U. S. Department of Defense, 2020, p. 216). 


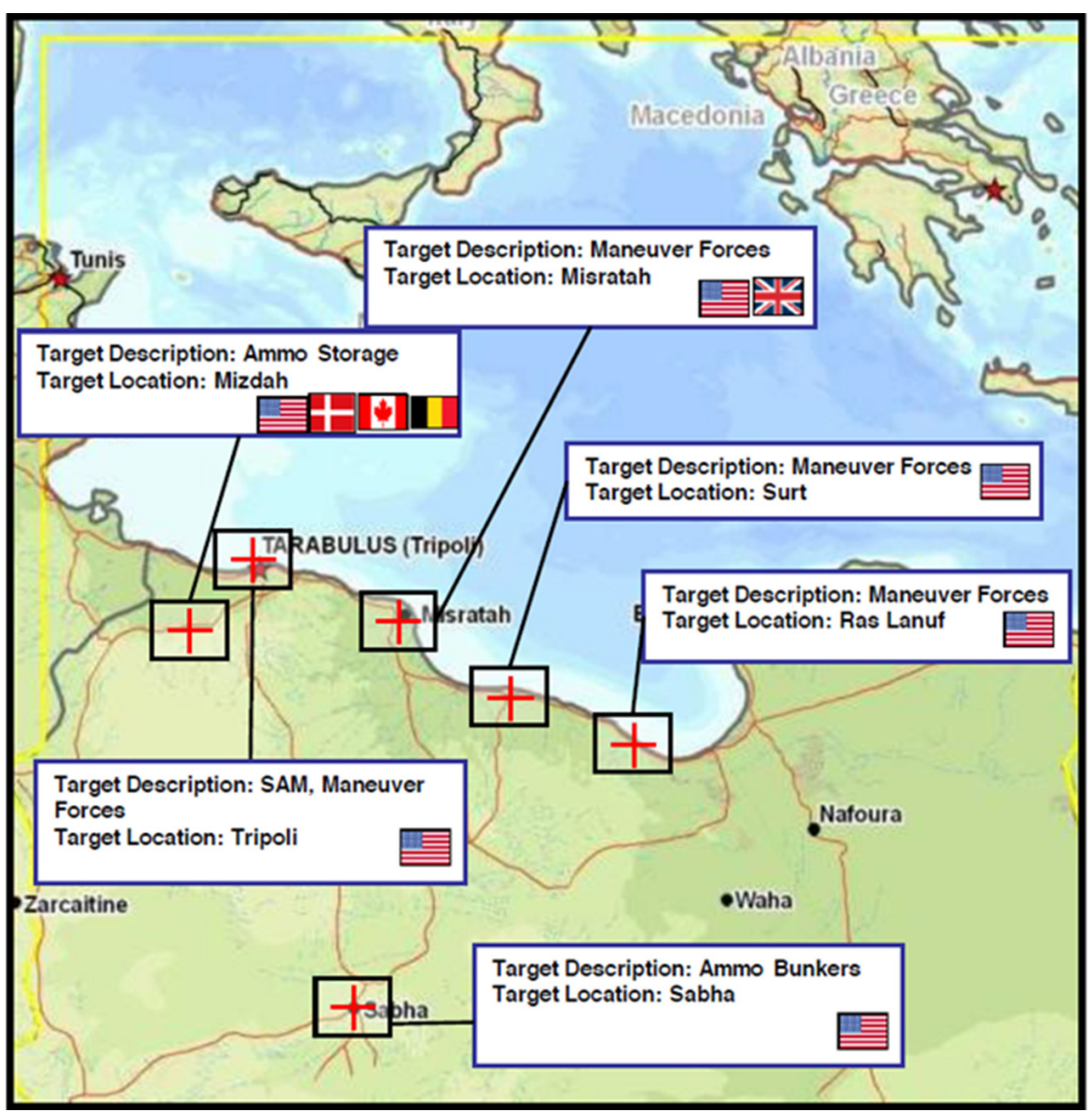

Figura 2. Ubicación de los objetivos atacados durante la Operación Odyssey Dawn, a corte 25 de marzo de 2011

Fuente: U. S. Department of Defense (2011)

http://archive.defense.gov/news/d20110328slides1.pdf

\section{Abril a agosto: Fuerte ofensiva de la OTAN y éxitos de la revolución al occidente}

Abril inicia con el nacimiento de la Operación Protector Unificado bajo el comando de la OTAN, por tanto, la coordinación entre los miembros de la coalición se facilita gracias a los canales ya existentes dentro de la alianza. Los esfuerzos de la organización se enfocaron en una fuerte campaña aérea en apoyo a la maniobra terrestre de los rebeldes, que buscaban derrotar a las 
fuerzas regulares mejor entrenadas y equipadas (Barrie, 2012). A pesar de lo simple que parece este postulado, el desempeño en combate de las fuerzas antigadafistas fue duramente cuestionado, pues el éxito operacional obtenido no era proporcional al apoyo brindado por la coalición. El avance era lento y, por lo tanto, costoso. Varios meses fueron necesarios para que el entrenamiento, la experiencia operacional y la unidad de mando facilitaran una ofensiva verdaderamente coordinada para empezar a derrotar las fuerzas del régimen (McGreal, 2011; Sotloff, 2011a, 2011b).

Dos batallas trascendentales marcaron el primer quinquemestre de la Operación Protector Unificado y garantizarían que para el final del periodo el control rebelde se extendiera por casi todo el país, quedando un último remanente de las fuerzas del régimen en Sirte.

\section{Batalla de Misurata (18 de febrero al 17 de agosto)}

Misurata, al oriente de Trípoli y parte de Tripolitania, es la tercera ciudad más grande de Libia, en 2010 contaba con una población estimada de 513.414 habitantes (World Population Review, 2020). La ciudad no era solo un escenario operacional para la revolución, sino que su consolidación por parte de los rebeldes significaba una victoria simbólica y psicológica, tan importante para contrarrestar la influencia de Gadafi que fue denominada el "Stalingrado de Libia" (Sengupta, 2011).

La batalla empieza al mismo tiempo que las manifestaciones en Bengasi, el 18 de febrero, logrando colapsar rápidamente las fuerzas de seguridad libias una semana después (Michael \& Schemm, 2011). Supuestamente, cuando Misurata cayó en manos de los rebeldes, Gadafi volteó a ver a sus generales y puso un vaso de agua sobre la mesa, lo regó y les dijo "[...] ahora pongan el agua otra vez dentro del vaso. Esto es Misurata” (Higgins, 2016). La contraofensiva de Gadafi a partir del 6 de marzo, que se hizo visible al oriente del país, también permitió el asedio de Misurata poco después de caer bajo el control rebelde.

La ciudad fue atacada sin mesura por fuego de artillería (incluyendo misilística), tanques y francotiradores pertenecientes a la $32^{\text {va }}$ Brigada Reforzada, también conocida como la "Brigada Khamis" en honor a su comandante, Khamis Gadafi, hijo menor del líder libio. De acuerdo con un cable diplomá- 
tico de la embajada estadounidense en Trípoli, filtrado por WikiLeaks (2011), la Brigada Khamis era "ampliamente conocida como la fuerza mejor entrenada y mejor equipada de la milicia libia”. Las fuerzas del régimen emplearon toda clase de acciones para contener a los rebeldes, incluyendo el uso de municiones de racimo contra civiles $^{30}$ (Human Rights Watch, 2011), lo que sumado a la escasez de combustible, agua y energía eléctrica impactó gravemente a la población, desatando una verdadera crisis humanitaria en Misurata.

A partir del mes de abril, gracias al apoyo de la OTAN, las fuerzas del régimen fueron paulatinamente expulsadas de la ciudad, extendiendo así los enfrentamientos a la periferia, lo que desataría las batallas de Zliten (21 de julio al 4 de agosto) y Tawergha ( 11 al 13 de agosto). La batalla se dio por terminada una vez los rebeldes anunciaron por radio el control total de la ciudad, el $17 \mathrm{de}$ agosto, e iniciaron una ofensiva hacia el sur con el fin de controlar la autopista que se dirige a Trípoli.

\section{Batalla de Trípoli (20 al 28 de agosto)}

A diferencia del resto del país, donde las manifestaciones de febrero tuvieron un éxito abrumador, en Trípoli las protestas fueron sofocadas por las fuerzas de seguridad mucho más asentadas en la capital. El régimen logró controlar la situación desde febrero hasta agosto, a pesar de la agresiva intervención de la OTAN. Los rebeldes, separados del epicentro militar y logístico de la revolución en Bengasi, optaron por aplicar tácticas de guerrillas urbanas para confrontar a las fuerzas de seguridad.

Por su parte, el régimen adoptó toda clase de medidas non sanctas para contener a los combatientes en la capital libia. Según reportó un residente de Trípoli, el 8 de abril dos vehículos fueron vistos en un suburbio ondeando la bandera tricolor de las fuerzas antigadafistas, "era una trampa, estos carros pertenecen a los sicarios de Gadafi. Cuando los manifestantes se reúnen alrededor de los carros empiezan a disparar contra los civiles” (Golovnina, 2011).

30 Producidas por la empresa española Instalaza S. A., las granadas MAT-120 son lanzadas desde morteros de calibre $120 \mathrm{~mm}$. Cada granada dispersa en el aire 21 submuniciones de $37 \mathrm{~mm}$ y 275 gr de peso de propósito antipersonal o antitanque. La munición fue vendida legalmente a Libia en 2008, antes de que España ratificara la Convención sobre Municiones en Racimo que obligaría a la destrucción de 1852 granadas MAT-120 en diciembre de 2008 y marzo de 2009 (Ministerio de Asuntos Exteriores y de Cooperación, 2014). 
El preludio de la Batalla de Trípoli fue una ofensiva desarrollada a través de las montañas Nafusa, desde las cuales los rebeldes se hicieron con el control de las ciudades a lo largo de la frontera con Túnez y la costa del mar Mediterráneo.

El 14 agosto los rebeldes tomaron las ciudades de Surman y Sabratha, al día siguiente la ofensiva logró la captura de Zawiyah. El 18 de agosto los rebeldes lograron el control de Garian, aislando a Trípoli de Sabha, capital de Fezán y la ciudad más importante del sur de Libia.

Sabha finalmente sería ocupada por fuerzas antigadafistas el 22 de septiembre, tras la Batalla de Sabha. Después de aislar a Trípoli de las ciudades circundantes, la población civil sufrió escasez de alimentos y combustible. La presión sobre el régimen implicaba entonces la eventual pérdida de su último bastión, pues con la liberación de la capital la supervivencia del régimen era imposible. El impacto internacional del asedio fue tal, que hasta ese momento solo 33 países ${ }^{31}$ habían reconocido al Consejo Nacional de Transición como máxima autoridad del Gobierno libio, diez días después el número aumentó a $71 .^{32}$

La noche del 21 de agosto, los rebeldes lograron hacerse con el control de gran parte de la capital en una ofensiva sin precedentes. Al día siguiente, Mahmud Nacua, charge d'affaires de la embajada libia en Londres, informó que los rebeldes controlaban ya el 95\% de Trípoli y que los combatientes estaban buscando incluso debajo de las piedras para hallar a Gadafi y llevarlo a juicio. De la misma forma, reportó la captura de Saif al-Islam y Muhammad, hijos del líder libio (Walt, 2011).

Saif al-Islam logra escapar el 24 de agosto y ofrece un cese al fuego a través de un e-mail enviado a Nic Robertson, corresponsal de CNN. En el texto aduce tener la autoridad para negociar en nombre del régimen e indica textualmente,

31 En orden cronológico por fecha de reconocimiento: Francia, Catar, Maldivas, Italia, Kuwait, Gambia, Jordania, Senegal, España, Australia, Emiratos Árabes Unidos, Alemania, Canadá, Panamá, Austria, Letonia, Lituania, Dinamarca, Cabo Verde, Bulgaria, Croacia, Turquía, Polonia, Países Bajos, Bélgica, Luxemburgo, Estados Unidos, Japón, Albania, Eslovenia, Montenegro, Reino Unido y Portugal.

32 Los 33 anteriores y en orden cronológico por fecha de reconocimiento, entre el 19 y el 30 de agosto de 2011: Gabón, Túnez, Nueva Zelanda, Egipto, Marruecos, Irlanda, Omán, Baréin, Nigeria, Malta, Irak, Grecia, Colombia, Noruega, Líbano, Corea del Sur, Sudán, Hungría, Chad, Etiopía, Burkina Faso, Serbia, Bosnia y Herzegovina, Mongolia, Yibuti, Costa de Marfil, Macedonia, Chipre, Malasia, Ruanda, Estonia, Benín, Níger, Togo, Guinea, República Checa, Filipinas y Eslovaquia. 
"trataré de salvar mi ciudad Trípoli y los dos millones de personas viviendo allí [...] De otra forma Trípoli estará perdida como Somalia [...] Pronto será un mar de sangre” (Kingdom of Bahrain Ministry of Interior, 2011).

La Batalla de Trípoli finaliza el 28 de agosto con la captura de la base militar de Salaheddin, nada menos que las instalaciones de la Brigada Khamis previamente involucrada en el asedio a Misurata. El ataque realizado por las fuerzas especiales del CNT fue precedido por un bombardeo de la OTAN, incluyendo el ataque a una casa justo a las afueras de las instalaciones. Majid Fayturi, un comandante rebelde oriundo de Misurata, se referiría al ataque de este último objetivo indicando que "hay una montaña de munición allí. La OTAN tiene el derecho de bombardear casas de esta manera” (News24, 2011). Junto a las instalaciones de la Brigada Khamis se halló una prisión donde fueron encontrados los cuerpos de 150 civiles ejecutados, de los cuales 53 ya habían sido incinerados (Gayle \& Jones, 2011), una tarea que evidentemente quedó a medias en razón al ataque.

Agosto finaliza y el control rebelde sobre la mayoría del territorio libio se hace evidente. Los meses subsiguientes de la guerra se enfocaron en el remanente del régimen ubicado en una región históricamente leal a Gadafi e influenciada desde Sirte. La OTAN reportó el avance de las operaciones militares con cierre a agosto de 2011, como se muestra en la figura 3.

\section{Septiembre y octubre, la liberación de Sirte y el fin de la dictadura}

Septiembre empieza con las fuerzas rebeldes consolidando el sur de Libia tras el éxito del asedio a Trípoli. Esta ofensiva en el sur fue conocida como la Campaña de Fezán, que permitió a los rebeldes hacerse con el control de las ciudades de Sabha, Brak, Murzuq, Hun, Waddan, Ubari y Ghat. La liberación del Distrito de Jufra, al sur del país, fue fundamental, pues incluyó la ocupación de una base aérea y 280 almacenes de armas y municiones (Radio Netherlands Worldwide, 2011). Desde mediados de septiembre, Libia se encontraba ya bajo control rebelde y la derrota del régimen era evidente. Las tropas que quedaban del Ejército libio se asentaron en Bani Walid y Sirte como últimos fortines del régimen. Los rebeldes lucharon en ambas ciudades simul- 


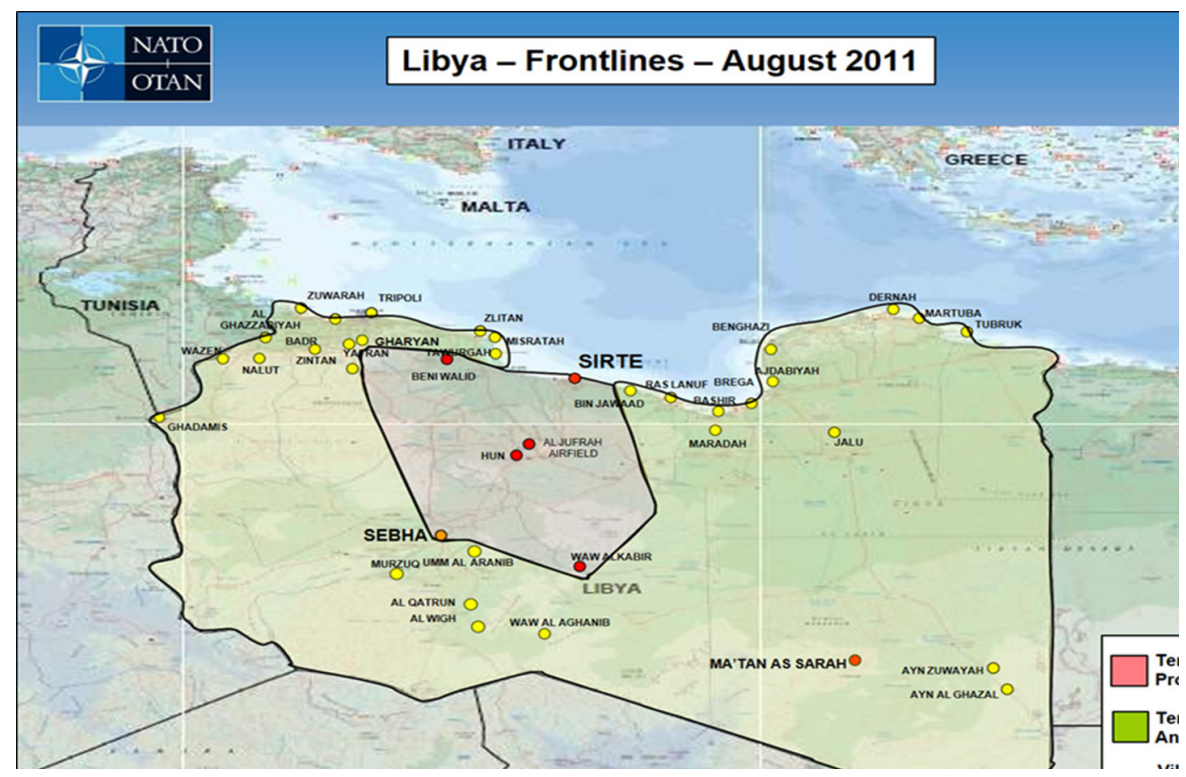

Figura 3. Frentes de Batalla, agosto de 2011

Fuente: OTAN (2011a)

https://www.nato.int/nato_static_fl2014/assets/pdf/pdf_2011_09/20110922_110922-libya-frontlines.pdf

táneamente, pero Bani Walid fue finalmente controlada el 17 octubre, tres días antes de la derrota final del régimen en Sirte.

Entre el 15 de septiembre y el 20 de octubre se desarrolló la Batalla de Sirte, oficialmente, la última batalla de la guerra civil libia que culminaría con la muerte de Muamar Gadafi. Precedidos por 292 ataques aéreos en las tres semanas previas, entre el 15 y el 18 de septiembre, los rebeldes atacaron sin éxito a Sirte desde el suroccidente, encontrando fuerte resistencia de las últimas tropas remanentes de la Brigada Khamis, que había instalado barricadas a lo largo de la línea costera. El 23 de septiembre, tropas rebeldes provenientes de Bengasi finalmente alcanzaron el extremo oriental de Sirte, lo que generó las condiciones para un supuesto asalto final. Los comandantes rebeldes Ahmed Zlitni y Osama Muttawa Swehly expresaron que parte de los alistamientos previos al ataque final incluyeron la evacuación de civiles que salían de la ciudad a un ritmo promedio de entre 400 y 500 vehículos al día (Al Jazeera, 2011). 
Entre el 24 y 25 de septiembre, los rebeldes atacaron por segunda vez la ciudad desde ambos frentes, pero nuevamente una fuerte resistencia de las tropas leales a Gadafi obligó a una "retirada táctica", tras un saldo de 9 combatientes muertos y 97 heridos. Igualmente, se reportó una gran presencia de civiles que no habían abandonado la ciudad a pesar de generarse las condiciones para hacerlo. Zeina Khodr (Khodr, 2011), corresponsal de Al Jazeera en el frente de batalla, indicó que era "muy difícil saber si estas personas de verdad quieren salir [de la ciudad] porque Gadafi realmente goza de apoyo en Sirte".

Un tercer intento por derrotar el remanente gadafista en Sirte se llevó a cabo entre el 26 y el 28 de septiembre. Esta vez, el asalto incluyó ataques aéreos de la OTAN y fuego de tanques pertenecientes al CNT que bombardearon el centro de la ciudad, afectando gravemente a civiles. La fuerte resistencia de las tropas gadafistas, la falta de coordinación entre las unidades rebeldes durante el desarrollo del asalto y las bajas causadas entre los mismos rebeldes, fueron las causas que obligaron su retiro a las afueras de la ciudad.

Los últimos días de septiembre no significaron grandes cambios en la dinámica operacional al interior de Sirte y la lucha pareció hacerse más férrea en Qasr Abu Hadi, un pequeño pueblo al sur de la ciudad. El lugar, que finalmente fue controlado por los rebeldes el 3 de octubre, representaba un objetivo simbólico para estos, por tratarse del lugar de nacimiento de Muamar Gadafi (Ahramonline, 2011).

El cuarto y último ataque inició el 7 de octubre, coordinando un avance rebelde desde los flancos sur, oriente y occidente. A las 4 horas de iniciado el asalto, el saldo era de 125 rebeldes heridos y 8 muertos, entre los que se destaca el coronel Amin El Turki, uno de los comandantes que lideraba la maniobra desde el occidente. Dos días más tarde, los rebeldes ya reportaban el control sobre importantes puntos de la ciudad, como el centro de convenciones, la universidad y el hospital principal de Sirte. Para el 12 de octubre los rebeldes ya controlaban gran parte de la ciudad y lograron la captura de Mutassim Gadafi, cuarto hijo del dictador, mientras trataba de escapar de Sirte en un vehículo civil. A pesar de los constantes esfuerzos de la coalición internacional y las tropas antigadafistas, los combatientes "se enfrentaron a una fuerza tan disciplinada y determinada que concluyeron que 
los defensores están protegiendo a un objetivo de alto valor, quizá incluso el mismo Gadafi” (El Gamal \& Gaynor, 2011)

El 20 de octubre, seis docenas de vehículos trataron de huir del centro de Sirte justo antes de la primera oración musulmana. A las 8:30 aviones caza franceses atacaron el convoy dejando como saldo 95 muertos.

Ellos habían sido claramente atacados por una fuerza de lejos mucho mayor al heterogéneo ejército organizado por los rebeldes durante los 8 meses de revolución para derrocar al una vez temido líder. Dentro de algunas de las camionetas y aun en sus asientos [se encontraban] sentados los restos óseos carbonizados de pasajeros y conductores muertos por el ataque. Menos de la mitad fueron quemados vivos dentro de los vehículos. Otros parecen haber sido liquidados, algunos partidos en dos por munición de gran calibre disparada desde aeronaves o sistemas terrestres. Otros parecen haber sido muertos por heridas de fragmentación, posiblemente por cohetes y munición explotando dentro de las camionetas (Gaynor \& Zargoun, 2011).

Increíblemente, Gadafi sobrevive al ataque y se esconde en una alcantarilla donde es hallado por los rebeldes al mediodía. Ahmed Al Sahati, uno de los combatientes, manifestó sarcásticamente: "él nos llamaba ratas, pero mire donde lo encontramos" (Gaynor \& Zargoun, 2011). Varios videos muestran a los rebeldes celebrando la captura de Gadafi quien, sangrando, pero vivo, es sostenido sobre el capó en una camioneta. Quien gobernó sin piedad por 42 años, pidió sin éxito misericordia por su vida. Aunque no existe una versión oficial de su muerte, algunos medios de comunicación informaron que su fallecimiento se dio por heridas de bala en su cabeza y pecho propinadas, al parecer, con su famosa pistola de oro.

La Operación Protector Unificado finaliza tras el desarrollo de 26.500 incursiones aéreas, de las cuales más de 9700 obedecieron a ataques. Estas operaciones ofensivas destruyeron 5900 objetivos militares, dentro los que destacan más de 600 tanques y 400 piezas de artillería. La cobertura marítima se extendió por 61.000 millas náuticas, dentro de las cuales 3100 embarcaciones fueron controladas y aproximadamente 300 abordadas por unidades de combate. Se le impidió la entrada o salida de Libia a once embarcaciones debido a que el contenido de su carga se consideró riesgoso para la población civil y más de 600 migrantes fueron rescatados por unidades navales en el Mediterráneo (OTAN, 2011d). 
Cada país participante en la Operación Protector Unificado acarreó con los costos derivados del sostenimiento de sus unidades aéreas y navales. La única capacidad militar perteneciente a la OTAN desplegada en Libia fue el sistema de alerta temprana y control aerotransportado ${ }^{33}$, cuyo costo estimado fue de 5.4 millones de euros al mes. Finalmente, el incremento del personal necesario para el funcionamiento de los cuarteles generales de la alianza para el desarrollo de la operación se estimó por su parte en 800.000 euros mensuales.

\section{Conclusiones}

Desde 1969, Muamar Gadafi centró la política exterior libia en contra de los intereses occidentales. Libia apoyó abiertamente organizaciones declaradas como terroristas, se opuso vehementemente al proceso de paz entre Egipto e Israel de 1978 y fue acusado de planificar un intento de asesinato contra el presidente egipcio Hosni Mubarak. Financió y planeó atentados terroristas que le valieron arduas sanciones económicas, y se acercó abiertamente al bloque soviético durante la Guerra Fría, lo que ocasionó embargos y sanciones de Estados Unidos desde 1973. Estados Unidos bombardeó Trípoli en 1986 como consecuencia de un atentado terrorista en Berlín, en el que murieron tres personas y 229 resultaron heridas. Esta operación militar estadounidense, dirigida a blancos militares, también incluyó un ataque a la residencia de Gadafi en el que supuestamente murió Hana, una hija adoptiva del dictador, de apenas seis meses de edad.

De la misma forma, sus relaciones con el Reino Unido se vinieron a pique con el atentado al vuelo Pan AM 103 en 1988 y el apoyo libio al Ejército Republicano Irlandés, con el suministro de armas. Francia, por su parte, habría sufrido el atentado al vuelo UTA 772 en 1989, culpando públicamente a Libia de haber patrocinado el atentado terrorista. Para mediados de la década de los noventa, Libia ya era un enemigo evidente de los Estados Unidos y, por

33 Conocido en inglés como Airborne Warning \& Control System (Awacs), el sistema de alerta temprana y control aerotransportado es un radar de largo alcance montado sobre un avión Boeing E-3A, capaz de identificar blancos aéreos y de superficie en un área de 310.798 kilómetros cuadrados. La OTAN cuenta actualmente con una flota de 14 de estas aeronaves (OTAN, 2020). 
extensión, de muchos de sus principales aliados. Tras la disolución de la Unión Soviética y la imposición de sanciones económicas, Libia no tuvo otra opción de capitular el apoyo al terrorismo y compensar económicamente a las víctimas.

En la práctica, y a pesar de argumentarse que la intervención estaba sustentada en la responsabilidad de proteger, las operaciones de la OTAN se orientaron claramente al cambio de régimen. La selección de blancos militares, la destrucción de infraestructura de defensa, la limitación del poder aéreo libio y el apoyo a la campaña terrestre de los rebeldes iban mucho más allá de un interés puramente humanitario, y eran, además, la consecuencia de una cadena de actos hostiles patrocinados por Libia desde la década de 1970 .

La intervención humanitaria en Libia ha generado profundas críticas alrededor de la responsabilidad de proteger y su premisa de evitar que, como en el pasado, "el hecho de que un Estado dejara de proteger a sus ciudadanos [fuera] un asunto que a nadie incumbía, sino que se viera como un motivo de preocupación del mundo entero" (United Nations, 2020). Las potencias que intervinieron en Libia instrumentalizaron la responsabilidad de proteger para generar el colapso del régimen gadafista a través del apoyo abierto a un actor no estatal. Aunque las guerras subsidiarias han sido una constante desde la segunda mitad del siglo XX, la guerra civil libia evidenció algo nunca antes visto, una alianza de defensa colectiva en apoyo al proyecto político de una insurgencia.

Aunque la narrativa que soporta a la responsabilidad de proteger es válida, su operativización es ciertamente utópica. La aparente falta de transparencia al tomarse la decisión sobre la intervención, las condiciones en que quedan los Estados intervenidos, así como los intereses propios de las alianzas que se tejen en torno al Consejo de Seguridad, hacen imposible que la responsabilidad de proteger se cumpla transparente y equitativamente en el sistema internacional.

En septiembre de 2011, cuando el colapso del régimen ya era predecible, el Consejo de Seguridad de las Naciones Unidas ya se preparaba para las subsiguientes operaciones de estabilidad necesarias para la resolución del conflicto. El 16 de septiembre de 2011, se emite la resolución 2009 que tuvo como finalidad principal la creación de la Misión de Apoyo de las Naciones Unidas en Libia (Unsmil), cuya función ha sido parcialmente modificada por 
las resoluciones 2022 (2011), 2040 (2012), 2095 (2013), 2144 (2014), 2238 (2015), 2323 (2016), 2376 (2017), y 2434 (2018).

Su mandato actual fue estipulado en la resolución 2486 (2019) que extendió su vigencia hasta el 15 de septiembre de 2020. La misión busca "dentro de las limitaciones operacionales y de seguridad" apoyar las instituciones clave libias y proveer bajo solicitud servicios esenciales y asistencia humanitaria. Entre otras funciones, la Unsmil monitorea y reporta la situación de derechos humanos, ayuda a evitar la proliferación de armas y lleva a cabo la coordinación de la asistencia internacional. Igualmente, provee asesoramiento al Gobierno de Acuerdo Nacional para estabilizar zonas de posconflicto, incluyendo aquellas liberadas del Estado Islámico (UNSMIL, 2020).

Tras la caída de Gadafi la multiplicidad de actores, el vacío de poder, así como la fragmentación tribal y política del pueblo libio hicieron imposible hallar la unidad nacional requerida para estabilizar el país. En 2014, el General Khalifa Haftar, actual comandante del Ejército Nacional de Libia, anunció en una rueda de prensa que el país se estaba moviendo en la dirección incorrecta y que el Congreso General de la Nación (CGN) lo llevaría "a un túnel oscuro del que sería muy difícil volver a salir” (Mahmoud, 2014). Con el rechazo de la autoridad del CGN, y tras un ataque militar perpetrado al parlamento en Trípoli, se inicia la Segunda Guerra Civil Libia, que desafortunadamente continúa desarrollándose en la actualidad.

Como se verá en los capítulos subsiguientes del presente libro, Libia no es el único ejemplo de la inaplicabilidad de los mecanismos de resolución de conflictos de Naciones Unidas. La Organización, establecida originalmente como órgano de gobernanza global entre Estados-nación, languidece frente a la adopción de medidas que brinden una solución integral a problemas atizados por actores no estatales. Tal incapacidad es, presumiblemente, una consecuencia del diseño organizacional y misional de la ONU, que, sin embargo, se agrava por las dinámicas internas de los miembros permanentes del Consejo de Seguridad.

La intervención en Libia ha sido el único caso en que el Consejo de Seguridad encontró consenso frente a la responsabilidad de proteger, quizá como consecuencia de la inesperada primavera árabe y la ola de cambios 
políticos que trajo en el panorama global. Aun así, la eficacia de la intervención sigue siendo puesta en duda tras las devastadoras consecuencias para la seguridad y estabilidad regional del Magreb, así como para la misma seguridad nacional libia.

\section{Referencias}

Ahramonline. (2011, October 3). Gaddafi Birthplace Abu Hadi Overrun. Ahram Online. http:// english.ahram.org.eg/NewsContent/2/8/23259/World/Region/Gaddafi-birthplace-AbuHadi-overrun.aspx

Alizadeh, H. (2012, enero 11). Un año de la muerte de Bouazizi, un año de revolución árabe. In Defence of Marxism. http://www.marxist.com/arab-revolution-first-anniversary-spanish. htm

Al Jazeera. (2011, September 24). Libyan Fighters Ready for Final Sirte Assault. Al Jazeera. https://www.aljazeera.com/news/africa/2011/09/201192444319839381.html

Al-Qadhafi, M. (1975). El Libro Verde (1ª ed.). Gran Yamahiriya Árabe Libia Popular Socialista. https://web.archive.org/web/20121114182152/http://free-news.org/PDFs/El_libro_ Verde_de_Gadafi.pdf

Al-Saadi, Y. (2012, March 19). Us Mercenary "Took Part” in Gaddafi Killing Sent to Assit Syrian opposition. Alakhbar. https://web.archive.org/web/20121015160608/http:// english.al-akhbar.com/content/blackwater-veteran-took-part-gaddafi-killing-asked-us-help-syrian-opposition

Asharq Al-awsat. (2011, February 9). Middle-east Arab News Opinion. Asharq Al-Awsat. https:// eng-archive.aawsat.com/theaawsat/news-middle-east/gaddafi-ready-for-libyas-day-of-rage

Ashton, C. (2011). Declaration by The High Representative on Behalf of The European Union on Events in Libya. Council of the European Union, 20. https://www.consilium.europa.eu/ uedocs/cms_data/docs/pressdata/en/cfsp/119397.pdf

Baldinetti, A. (2014). The Origins of the Libyan Nation: Colonial Legacy, Exile and the Emergence of a New Nation-State. Routledge.

Barrie, D. (2012). Libya's Lessons: The Air Campaign. Survival, 54(6), 57-65.

Bates, S. (2011, February 28). Don't Mess with The Queen, Muammar! The Guardian. https:// www.theguardian.com/uk/2011/feb/28/queen-freezes-gaddafi-assets

Bazzi, M. (2011, May 27). What Did Qaddafi's Green Book Really Say? The New York Times. https://www.nytimes.com/2011/05/29/books/review/what-did-qaddafis-green-book-really-say.html

BBC News. (2011, February 18). Libya: Benghazi Clashes Deadly - Witnesses. BBC News. https://www.bbc.com/news/world-africa-12506787

Borger, J., \& Chulov, M. (2011, May 30). Al-Jazeera Footage Captures 'Western Troops on The Ground' In Libya. The Guardian. https:/www.theguardian.com/world/2011/may/30/ western-troops-on-ground-libya 
Brace, R. (1972). Reviewed Work: Libyan Independence and the United Nations by Adrian Pelt. The International Journal of African Historical Studies, 5(3), 488-490. https://doi. org $/ 10.2307 / 217101$

Bright, M. (2002, November 10). MI6 Halted Bid to Arrest Bin Laden. The Guardian. https:// www.theguardian.com/politics/2002/nov/10/uk.davidshayler

Cembrero, I. (2011, febrero 18). El Día de la Ira en Libia se salda con varios muertos por disparos. El Pais. https://elpais.com/diario/2011/02/18/internacional/1297983608_850215.html

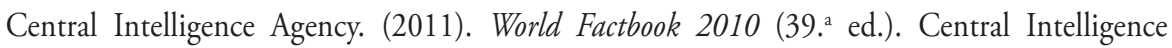
Agency. https://www.cia.gov/library/publications/download/download-2010/index.html

Claiborne, C. (2011, August 7). The Assassination of General Abdul Fattah Younis. Daily Kos. https://www.dailykos.com/story/2011/8/7/1002918/-

Daalder, I., \& Stavridis, J. (2011, October 30). NATO's Success in Libya. The New York Times. https://www.nytimes.com/2011/10/31/opinion/31iht-eddaalder31.html

Dainotti, A., Squarcella, C., Aben, E., Claffy, K., Chiesa, M., Russo, M., \& Pescapé, A. (2011). Analysis of Country-Wide Internet Outages Caused by Censorship [Proceedings of the 2011 ACM SIGCOMM conference on Internet measurement conference]. https://dl.acm.org/ doi/10.1145/2068816.2068818

Dziadosz, A. (2011, February 23). Benghazi, Cradle of Revolt, Condemns Gaddafi. Reuters. https://www.reuters.com/article/us-libya-protests-east-idUSTRE71M1Q920110223

El Gamal, R., \& Gaynor, T. (2011, October 19). Libya Forces Relaunch Sirte Assault After Setback. Reuters. https://www.reuters.com/article/us-libya/libya-forces-relaunch-sirte-assault-after-setback-idUSTRE79F1FK20111019

Eppel, S. (2006, April 8). 'Healing the Dead': Exhumation and Reburial as Truth-Telling and Peace-Building Activities in Rural Zimbabwe. Centre for Justice \& Reconciliation. http:// restorativejustice.org/rj-library/healing-the-dead-exhumation-and-reburial-as-truth-telling-and-peace--building-activities-in-rural-zimbabwe/6985/\#sthash.DhWyDb8n.dpbs

Erlanger, S. (2011, March 20). Sarkozy Puts France at Vanguard of West's War Effort. The New York Times. https://www.nytimes.com/2011/03/21/world/europe/21france.html

Fadel, L., \& Raghavan, S. (2011, February 21). Military Helicopters Reportedly Fire on Protesters in Libya. The Washington Post. http://www.washingtonpost.com/wp-dyn/ content/article/2011/02/20/AR2011022004185.html

Fahim, K., \& Baume, M. (2011, May 12). Head of French Company Is Killed in Libyan City. The New York Times. https://www.nytimes.com/2011/05/13/world/africa/13benghazi. html

Faraon, M., Atashi, S., Kaipainen, M., \& Gustafsson, N. (2011). Using Circumventing Media to Counteract Authoritarian Regimes. En B. Gunilla, D. Whitehouse, G. Singh (Ed.), Proceedings of the IADIS International Conference ICT, Society and Human Beings 2011 (pp. 251-254). IADIS Press. http://urn.kb.se/resolve?urn=urn:nbn:se:sh:diva-12962

Galal, O. (2011, February 22). Arab League Bars Libya From Meetings, Citing Forces' 'Crimes'. Bloomberg. https://www.bloomberg.com/news/articles/2011-02-22/arab-league-bars-libya-from-meetings-citing-forces-crimes- 
Gayle, D., \& Jones, B. (2011, August 28). Horror Of 150 Bodies Found on A Farm Thought To Have Been Massacred By Pro-Gaddafi Forces Daily Mail. https://www.dailymail.co.uk/ news/article-2030782/Libya-Horror-150-bodies-farm-thought-massacred-pro-Gaddafiforces.html

Gaynor, T., \& Zargoun, T. (2011, October 21). Gaddafi Caught Like "Rat" in A Drain, Humiliated And Shot. Reuters. https://www.reuters.com/article/us-libya-gaddafi-finalhours-idUSTRE79K43S20111021

Golovnina, M. (2011, April 11). Rebels Resort to Guerrilla Tactics in Western Libya. Reuters. https://www.reuters.com/article/us-libya-guerrilla/rebels-resort-to-guerrilla-tactics-inwestern-libya-idUSTRE73A2H020110411

Government of Canada. (2014, February 22). Operation MOBILE [Education and awareness]. https://www.canada.ca/en/department-national-defence/services/operations/military-operations/recently-completed/operation-mobile.html

Higgins, E. (2016, April 8). Interview with Kevin Dawes on His Time in Libya. Bellingcat. https://www.bellingcat.com/news/mena/2016/04/08/interview-with-kevin-dawes-onhis-time-in-libya/

Hjärpe, J. (1976). Religion and Ideology: Mu'ammar Al-Kadhdhafi, Islam And The "Third International Theory". Scripta Instituti Donneriani Aboensis, 9, 56-71. https://doi. org/10.30674/scripta.67108

Hofmann, U. (2005). Was Atlantis a Bronze Age Metropolis in North Africa? https://www. atlantis-scout.de/HofmannU_2005_AtlantisBronzeAgeMetropolisNorthAfrica.pdf

Human Rights Watch. (2011, April 15). Libya: Cluster Munitions Strike Misrata. Human Rights Watch. https:/www.hrw.org/news/2011/04/15/libya-cluster-munitions-strike-misrata

Hunter, B. (1991). Libya. En B. Hunter (Ed.), The Statesman's Year-Book: Statistical and Historical Annual of the States of the World for the Year 1991-1992 (pp. 812-816). Palgrave Macmillan UK.

Hweio, H. (2012). Tribes in Libya: From Social Organization to Political Power. African Conflict and Peacebuilding Review, 2(1), 111-121.

Interfax. (2011, agosto 23). Старший сын Каддафи утверждает, что в Триполи воюют подразделения НАТО и наемники [El hijo mayor de Gadafi afirma que las unidades de la OTAN y los mercenarios están luchando en Trípoli]. Interfax. https://www.interfax.ru/ russia/204759

International Institute for Strategic Studies. (2010a). Chapter Five: Middle East and North Africa. The Military Balance, 110(1), 235-282. https://doi.org/10.1080/04597220903545841

International Institute for Strategic Studies. (2010b). Chapter Two: Latin America and the Caribbean. The Military Balance, 110(1), 53-102. https://doi. org/10.1080/04597220903545817

JFC NAPLES - Allied Joint Force Command Naples. (s. f.). What is JFC Naples? JFC NAPLES Allied Joint Force Command Naples. https://jfcnaples.nato.int/page5714813.aspx

Joyce, P., \& Wain, N. (2014). Palgrave Dictionary of Public Order Policing, Protest and Political Violence. Palgrave Macmillan. 
Kessler, O. (2011, February 21). “Libyan Soldiers Defect to Protesters' Side in Benghazi”. The Jerusalem Post. https://www.jpost.com/Middle-East/Libyan-soldiers-defect-to-protestersside-in-Benghazi

Khodr, Z. (2011, September 25). Libyan NTC Fighters Pull Back from Sirte. Al Jazeera. https:// www.aljazeera.com/news/africa/2011/09/2011925104532777522.html

Kingdom of Bahrain Ministry of Interior. (2011, August 25). Gadhafi Son Offers to Broker Libya Cease-Fire. https://www.policemc.gov.bh/en/news/world/11024/

Komsomolskaya Pravda. (2011, abril 6). На стороне Каддафи воюют белорусские партизаны [Los partisanos bielorrusos luchan del lado de Gadafi]. Komsomolskaya Pravda. https://www.kp.ru/daily/25664/825870/

La Boda, S. (1994). International Dictionary of Historic Places: Middle East and Africa. Taylor \& Francis.

Ladjal, T. (2016). Tribe and State in The History of Modern Libya: A Khaldunian Reading of The Development of Libya in The Modern Era 1711-2011. Cogent Arts \& Humanities, 3(1), 1-17. https://doi.org/10.1080/23311983.2016.1183278

Larson, C. (2011, abril 5). The Mind of Muammar. Foreign Policy. https://foreignpolicy. com/2011/04/05/the-mind-of-muammar/

London Evening Standard. (2011, February 17). Pro-Gaddafi Forces «Kill 14 Protesters in Day of Rage». London Evening Standard. https://web.archive.org/web/20110225005126/ http://www.thisislondon.co.uk/standard/article-23924340-pro-gaddafi-forces-kill-14protesters-in-day-of-rage.do

Lutterbeck, D. (2009). Arming Libya: Transfers of Conventional Weapons Past and Present. ContemporarySecurityPolicy,30(3),505-528.https://doi.org/10.1080/13523260903327451

Mahmoud, K. (2014, May 22). Khalifa Haftar: My Forces Will Reach Tripoli Soon. Asharq Al-awsat. https://web.archive.org/web/20140712012422/http://www.aawsat. net/2014/05/article55332486

Makariusová, R., \& Ludvík, Z. (2012). Non-State Military Actors: The Case of the 2011 Libyan Conflict. Central European Journal of International and Security Studies, 14(2), 244-268.

Mann, M. (2005). The Dark Side of Democracy: Explaining Ethnic Cleansing. Cambridge University Press.

Mattes, H. (2004). Challenges to Security Sector Governance in The Middle East: The Libyan Case [Conference Paper presented at Geneva Centre for the Democratic Control of Armed Forces, "Challenges of Security Sector Reform in the Middle East", Geneva, Switzerland].

McGreal, C. (2011, March 30). Undisciplined Libyan Rebels No Match for Gaddafi's Forces. The Guardian. https://www.theguardian.com/world/2011/mar/30/libyan-rebels-nomatch-gaddafi

Michael, M., \& Schemm, P. (2011, February 23). Clampdown in Tripoli As Protests Close In. Press Herald. https://www.pressherald.com/2011/02/23/clampdown-in-libyan-capital-as-protests-close-in/

MinisteriodeAsuntosExterioresydeCooperación.(2014).Informeconformealarticulo 7 correspondienteal año2013. Convenciónsobremunicionesderacimo.https://www.unog.ch/80256EDD006B8954/ (httpAssets)/D87446B5D339068AC1257CF900541576/\$file/2014Spain.pdf 
Mokhefi, M. (2011). Gaddafi's regime in relation to the Libyan tribes. Al Jazeera Centre for Studies, 20.

Moniz, L. (2017). The Uprising in Libya. En L. Moniz (Ed.), The Second Cold War: Geopolitics and the Strategic Dimensions of the USA (pp. 157-168). Springer International Publishing. https://doi.org/10.1007/978-3-319-54888-3_13

Moreno, J. (2014). Invaders or Just Herders? Libyans in Egypt in The Third and Second Millennia Bce. World Archaeology, 46(4), 610-623. https://doi.org/10.1080/00438243. 2014.931820

Mueller, K (Ed.). (2015). Precision and Purpose: Airpower in The Libyan Civil War. Rand Corporation.

News24. (2011, August 27). Rebels Capture Last Army Base in Tripoli. News24. https://www. news24.com/Africa/News/Rebels-capture-last-army-base-in-Tripoli-20110827

Ngwenya, D. (2017). Healing the Wounds of Gukurahundi in Zimbabwe: A Participatory Action Research Project (Vol. 19). Springer International Publishing.

Non-Aligned Movement. (2020). NAM Members States. https://mnoal.org/nam-members/

Norton-Taylor, R., \& Stephen, C. (2011, May 31). Libya: SAS Veterans Helping NATO Identify Gaddafi Targets in Misrata. The Guardian. https:/www.theguardian.com/world/2011/ may/31/libya-sas-veterans-misrata-rebels

Olivier, B. (1980). The Faces of Gaddafi. Africa Insight, 10(2), 87-90.

OTAN. (1949, abril 4). Tratado del Atlántico Norte. OTAN. http://www.nato.int/cps/fr/natohq/ official_texts_17120.htm

OTAN. (2011a). Evolution of The Frontlines in Libya-March-September. 2011. OTAN. https://www.nato.int/cps/en/natohq/photos_78403.htm?selectedLocale=en

OTAN. (2011b). Map: Operation Unified Protector. OTAN. http://www.nato.int/nato_static/ assets/pdf/pdf_2011_07/20110708_110708-map_OUP_Libya.pdf

OTAN. (2011c). Operation Unified Protector, Protection of Civilians and Civilian-Populated Areas \& Enforcement of the No-Fly Zone. OTAN. https://www.nato.int/nato_static_ fl2014/assets/pdf/pdf_2011_10/20111005_111005-factsheet_protection_civilians.pdf

OTAN. (2011d). Operation Unified Protector Final Mission Stats. OTAN. https://www.nato.int/ nato_static_fl2014/assets/pdf/pdf_2011_11/20111108_111107-factsheet_up_factsfigures_en.pdf

OTAN. (2020). Awacs: NATO's "Eyes in The Sky”. OTAN. http://www.nato.int/cps/en/natohq/ topics_48904.htm

Radio Netherlands Worldwide. (2011, September 9). Libyan Oasis of Jufra is NTC's Key Target. Radio Netherlands Worldwide. https://web.archive.org/web/20120821211336/http://cdn. radionetherlands.nl/africa/bulletin/libyan-oasis-jufra-ntcs-key-target

Radov, Z. (2011, marzo 1). В Ливии на стороне правительства воюет немало зимбабвийцев [En Libia, muchos zimbabwenses están luchando del lado del gobierno]. Komsomolskaya Pravda. https://www.kp.ru/daily/25645/809127/ 
RIA Novosti. (2018, febrero 2). Источник: Освобожденный из плена в Ливии белорусский военный прибыл в Минск [Fuente: Soldado bielorruso liberado de su cautiverio en Libia llegó a Minsk]. RIA Novosti. https://ria.ru/20180202/1513834267.html

Roxborough, I. (2007). Counterinsurgency. Contexts, 6(2), 15-21.

Sengupta, K. (2011, April 17). Misrata Becomes Libya's Stalingrad. The Independent. http:// www.independent.co.uk/news/world/africa/misrata-becomes-libyas-stalingrad-2269008. html

Shavitt, Y., \& Zilberman, N. (2012). Arabian Nights: Measuring The Arab Internet During the 2011 Events. IEEE Network, 26(6),75-80. https://doi.org/10.1109/MNET.2012.6375897

Siebens, J., \& Case, B. (2012). The Libyan civil war: Context and consequences. THINK International and Human Security.

Smith, D. (2011, February 22). Has Gaddafi Unleashed A Mercenary Force on Libya? The Guardian. https://www.theguardian.com/world/2011/feb/22/gaddafi-mercenary-force-libya

Sotloff, S. (2011a, July 1). Libya’s Rebels Grow Wary of Western Journalists. Time. http:// content.time.com/time/world/article/0,8599,2081020,00.html

Sotloff, S. (2011b, August 21). Libya's Long Endgame: Which Rebels Exactly Are Gaining on Gaddafi in Tripoli? Time. http://content.time.com/time/world/article/0,8599,2089680,00. html

St John, R. (1982). The Soviet Penetration of Libya. The World Today, 38(4), 131-138.

U. S. Department of Defense. (2011, March 28). Libya: Situation Update, 25 Mar. U.S. Department of Defense. http://archive.defense.gov/news/d20110328slides1.pdf

U. S. Department of State. (2004, January 1). Background Note: Libya. U.S. Department of State. https://2001-2009.state.gov/r/pa/ei/bgn/5425.htm

U. S. Department of State. (2020). Foreign Terrorist Organizations. U.S. Department of State. //2009-2017.state.gov/j/ct/rls/other/des/123085.htm

U. S. Department of Defense. (2020). Dictionary of Military and Associated Terms. http://www. jcs.mil/Portals/36/Documents/Doctrine/pubs/dictionary.pdf

U. N. Security Council. (2011a). Resolution 1970. United Nations. http://www.icc-cpi.int/NR/ rdonlyres/081A9013-B03D-4859-9D61-5D0B0F2F5EFA/0/1970Eng.pdf

U. N. Security Council. (2011b). Resolution 1973. United Nations. https://www.nato.int/nato_ static_fl2014/assets/pdf/pdf_2011_03/20110927_110311-UNSCR-1973.pdf

U. N. Security Council. (2011c, March 17). Security Council Approves 'No-Fly Zone' over Libya, Authorizing 'All Necessary Measures' to Protect Civilians, by Vote of 10 in Favour with 5 Abstentions. https://www.un.org/press/en/2011/sc10200.doc.htm

United Nations. (2003, September 13). Security Council Lifts Sanctions Imposed on Libya After Terrorist Bombings of Pan AM 103, UTA 772 Meetings Coverage and Press Releases. https:// www.un.org/press/en/2003/sc7868.doc.htm

United Nations. (2011a, February 26). Secretary-General's Remarks to The Security Council on Libya. United Nations Secretary-General. https://www.un.org/sg/en/content/sg/statement/2011-02-26/secretary-generals-remarks-security-council-libya-scroll-down-arabic 
United Nations. (2011b, March 18). Libya: Ban Welcomes Security Council Authorization of Measures to ProtectCivilians. UNNews. https://news.un.org/en/story/2011/03/369392-libya-ban-welcomes-security-council-authorization-measures-protect-civilians

United Nations. (2020). La responsabilidad de proteger y las Naciones Unidas. United Nations. https://www.un.org/es/chronicle/article/la-responsabilidad-de-proteger-y-las-naciones-unidas

United Nations Support Mission in Libya. Unsmil. (2020). Mandate. United Nations Support Mission in Libya. Unsmil. https://unsmil.unmissions.org/mandate

Vandewalle, D. (2012). A History of Modern Libya (2. ${ }^{\text {a }}$ ed.). Cambridge University Press.

Von Rohr, M. (2011, July 26). Settling Old Scores: Tribal Rivalries Complicate Libyan War. Der Spiegel. https://www.spiegel.de/international/world/settling-old-scores-tribal-rivalries-complicate-libyan-war-a-776695.html

Walt, V. (2011, August 22). Libyan Rebels Take Most of Tripoli: Where's Muammar? Time. http://content.time.com/time/world/article/0,8599,2089702,00.html

Warbrick, C. (2012). British Policy and the National Transitional Council of Libya. The International and Comparative Law Quarterly, 61(1), 247-264.

Weaver, M. (2008, November 21). Families of Lockerbie Bombing Victims Receive Compensation from Libya. The Guardian. https://www.theguardian.com/uk/2008/ nov/21/lockerbie-libya

Wikileaks. (2011, January 31). Libyan Succession: Qadhafi Orchestrating the Boys' High Wire Act? The Telegraph. https://www.telegraph.co.uk/news/wikileaks-files/libya-wikileaks/8294686/ LIBYAN-SUCCESSION-QADHAFI-ORCHESTRATING-THE-BOYS-HIGHWIRE-ACT.html

Wikstrom, C. (2011, February 3). Calls for Weekend Protests in Syria. Al Jazeera. https://www. aljazeera.com/news/middleeast/2011/02/201122171649677912.html

World Population Review. (2020). Misratah Population 2020 (Demographics, Maps, Graphs). World Population Review. https://worldpopulationreview.com/world-cities/misratah-population/

Youssef, N. (2011, March 28). Libyan Rebels Push West into Less Friendly Territory. Impact2020. https:/www.mcclatchydc.com/news/nation-world/world/article24618592.html 